Key Words:

Aluminosilicate Evaporator Scaling Glass Frit

High Level Waste

Retention:

Permanent

\title{
FORMATION AND DEPOSITION OF ALUMINOSILICATES IN SUPPORT OF THE 2H EVAPORATOR FOULING PROGRAM (U)
}

\author{
Scott Rosencrance \\ David Herman \\ David Healy
}

OCTOBER 2001

Westinghouse Savannah River Company

Savannah River Site

Aiken, SC 29808

Prepared for the U.S. Department of Energy Under

Contract Number DE-AC09-96SR18500 
This document was prepared in conjunction with work accomplished under Contract No. DE-AC09-96SR18500 with the U. S. Department of Energy.

\section{DISCLAIMER}

This report was prepared as an account of work sponsored by an agency of the United States Government. Neither the United States Government nor any agency thereof, nor any of their employees, makes any warranty, express or implied, or assumes any legal liability or responsibility for the accuracy, completeness, or usefulness of any information, apparatus, product or process disclosed, or represents that its use would not infringe privately owned rights. Reference herein to any specific commercial product, process or service by trade name, trademark, manufacturer, or otherwise does not necessarily constitute or imply its endorsement, recommendation, or favoring by the United States Government or any agency thereof. The views and opinions of authors expressed herein do not necessarily state or reflect those of the United States Government or any agency thereof.

This report has been reproduced directly from the best available copy.

Available for sale to the public, in paper, from: U.S. Department of Commerce, National Technical Information Service, 5285 Port Royal Road, Springfield, VA 22161, phone: (800) 553-6847, fax: (703) 605-6900

email: orders@ntis.fedworld.gov

online ordering: http://www.ntis.gov/help/index.asp

Available electronically at http://www.osti.gov/bridge

Available for a processing fee to U.S. Department of Energy and its contractors, in paper, from: U.S. Department of Energy, Office of Scientific and Technical Information, P.O. Box 62, Oak Ridge, TN 37831-0062,

phone: (865)576-8401,

fax: (865)576-5728

email: $\underline{\text { reports@ adonis.osti.gov }}$ 
Key Words:

Aluminosilicate Evaporator Scaling Glass Frit

High Level Waste

Retention:

Permanent

\title{
FORMATION AND DEPOSITION OF ALUMINOSILICATES IN SUPPORT OF THE 2H EVAPORATOR FOULING PROGRAM (U)
}

\author{
Scott Rosencrance \\ David Herman \\ David Healy
}

OCTOBER 2001

Westinghouse Savannah River Company

Savannah River Site

Aiken, SC 29808

Prepared for the U.S. Department of Energy Under

Contract Number DE-AC09-96SR18500 
This page was intentionally left blank 


\section{TABLE OF CONTENTS}

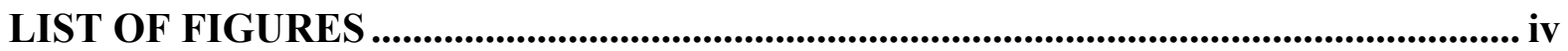

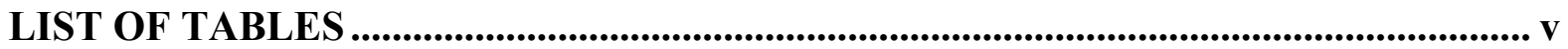

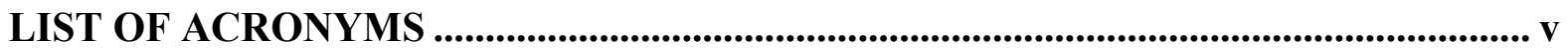

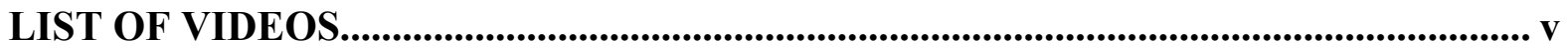

1.0 BACKGROUND .............................................................................................................................. 1

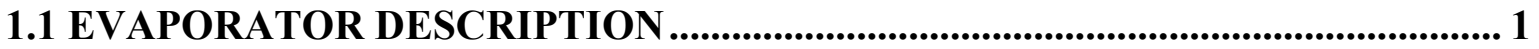

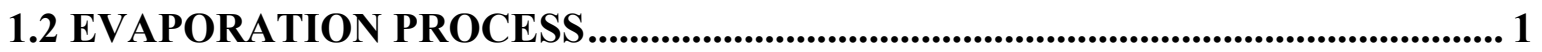

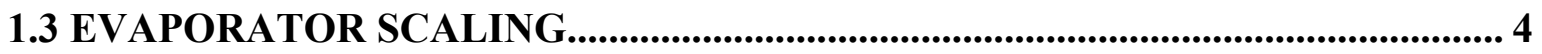

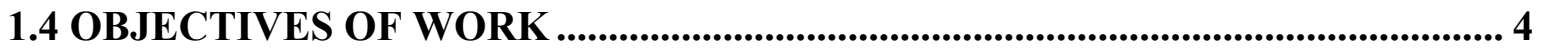

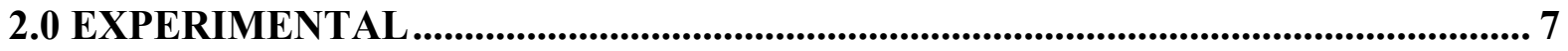

2.1 PREPARATION OF SILICON SOLUTION ................................................... 7

2.2 PREPARATION OF ALUMINUM SOLUTION ................................................... 7

2.3 PREPARATION OF THE SIMULATED EVAPORATOR FEED .......................... 7

2.4 BATCH TESTING METHODOLOGY ............................................................ 7

2.5 CONTINUOUS TESTING METHODOLOGY ................................................ 9

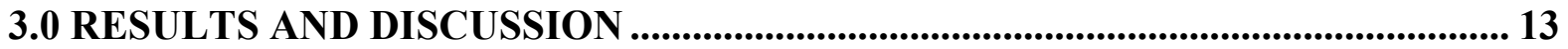

3.1 BATCH DEPOSITION TESTING .................................................................. 13

3.1.1 Unmixed Deposition Testing .............................................................................................. 13

3.1.2 Low Mixing Deposition Testing ............................................................................... 18

3.1.3 High Mixing Deposition Testing ..................................................................... 19

3.1.4 Observed Effect of Mixing............................................................................ 20

3.1.5 Pre-formation Tests.................................................................................... 21

3.1.6 High Mixing and Pre-formation in Tandem....................................................... 22

3.1.7 Summary of Batch Testing Results.......................................................................... 23

3.2 CONTINUOUS FEED RESULTS .......................................................................... 23

3.2.1 Unmixed Deposition Testing ....................................................................... 24

3.2.2 Low Mixing Continuous Testing............................................................................ 29

3.2.3 High Mixing Continuous Testing.................................................................................. 29

3.2.4 Seeding/High Mixing Continuous Testing ........................................................... 30

3.2.5 Summary of continuous Testing Results .................................................................... 38

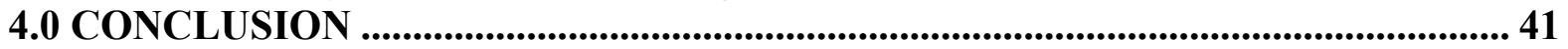

5.0 REFERENCES....................................................................................................... 43 


\section{LIST OF FIGURES}

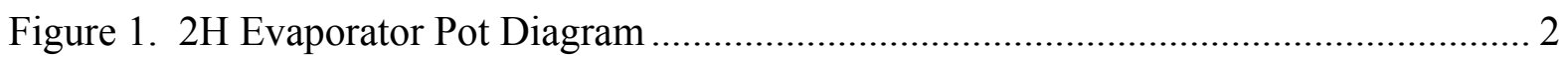

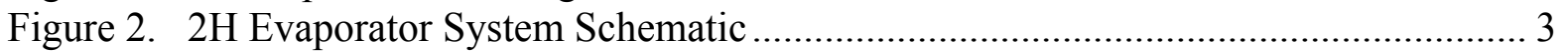

Figure 3. 2H Evaporator on 4/30/01 before cleaning ...................................................... 5

Figure 4. 2H Evaporator on 6/7/01 after cleaning. .......................................................... 5

Figure 5. Left bottle - Aluminum solution (Section 2.1); Right bottle - Silicon-rich solution (Section 2.2).

Figure 6. Batch testing apparatus consisting of stainless steel beaker immersed in water bath

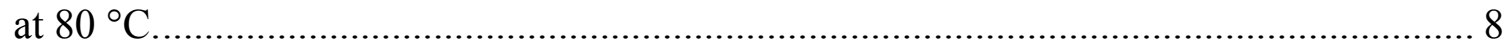

Figure 7. Continuous deposition testing apparatus ......................................................... 10

Figure 8. Stainless steel beaker after reaction for the unmixed batch test............................ 14

Figure 9. X-ray diffraction for deposited solids from unmixed batch test............................ 15

Figure 10. X-ray diffraction for non-deposited solids from unmixed batch test .................. 15

Figure 11. Scanning electron microscopy of deposited solids from unmixed batch test...... 16

Figure 12. Scanning electron microscopy of non-deposited solids from unmixed batch test.

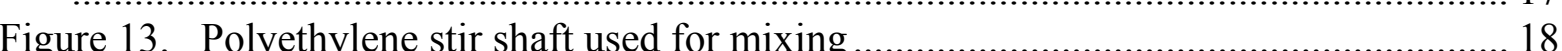

Figure 14. Stainless steel beaker after reaction for the low mixing batch test...................... 19

Figure 15. Stainless steel beaker after reaction for the high mixing batch test .................... 20

Figure 16. Stainless steel beaker after reaction for a two-hour preformed test .................... 23

Figure 17. Stainless steel beaker after reaction for unmixed continuous test....................... 25

Figure 18. X-ray diffraction spectrum of solids from beaker wall of unmixed continuous test

Figure 19. X-ray diffraction spectrum for non-deposited solids from continuous unmixed

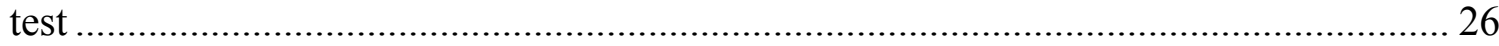

Figure 20. Scanning electron microscopy of deposited solids from unmixed continuous test

Figure 21. Scanning electron microscopy of non-deposited solids from unmixed continuous

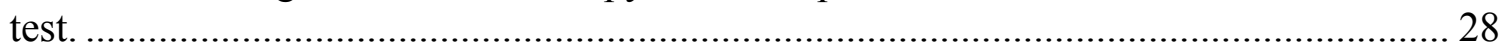

Figure 22. Stainless steel beaker after reaction for the low mixing continuous test.............. 29

Figure 23. Stainless steel beaker after reaction for the high mixing continuous test............. 30

Figure 24. Stainless steel beaker after reaction for the seeded continuous test ...................... 31

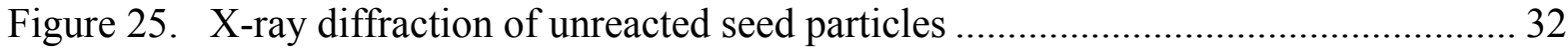

Figure 26. X-ray diffraction spectrum of deposited solids for seeded continuous test.......... 33

Figure 27. X-ray diffraction spectrum of non-deposited solids from seeded continuous test

Figure 28. Scanning electron microscopy of unreacted seed particles ................................ 35

Figure 29. Scanning electron microscopy of deposited solids from seeded continuous test 36

Figure 30. Scanning electron microscopy of non-deposited solids from seeded continuous

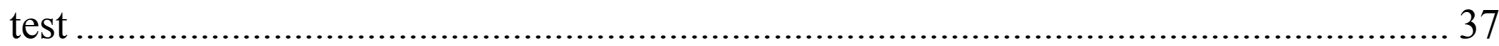

Figure 31. Scanning electron microscopy of an unreacted coarse seed following reaction in

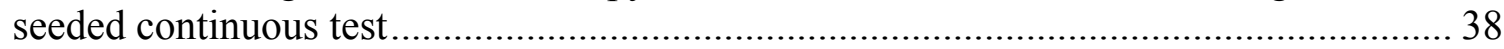




\section{LIST OF TABLES}

Table 1. Summary of Results for Batch Testing ................................................................ 22

Table 2. Summary of Mixing Effects in Continuous Feed Testing ...................................... 38

Table 3. Summary of seeding Effects in Continuous Feed Testing....................................... 39

\section{LIST OF ACRONYMS}

DWPF Defense Waste Processing Facility

GDL Gravity Discharge Line

ICP-ES Inductively Coupled Plasma-Emission Spectroscopy

\section{LIST OF VIDEOS}

Batch Testing Video

Continuous Testing Video 
This page intentionally left blank. 
WSRC-TR-2001-00464, REVISION 0

\subsection{BACKGROUND}

\subsection{EVAPORATOR DESCRIPTION}

The $2 \mathrm{H}$ Evaporator, located in the $\mathrm{H}$-Area tank farm, was designed to concentrate radioactive waste from H-Area canyons. ${ }^{1}$ The evaporator pot is a 304-L stainless steel vessel, 8 feet in diameter and 16.5 feet tall, with a nominal operating capacity of about 2000 gallons. The pot is designed for an operating pressure of $14 \mathrm{psig}$. The internal pressure is determined primarily by pressure drop through the demister and vapor condenser. The evaporator temperature is determined by the desired salt solution concentration in the evaporator heel. The waste can be concentrated until a salt solubility limit is reached, which is approximately $160^{\circ} \mathrm{C}$. A typical operating temperature for the $2 \mathrm{H}$ evaporator is $125-140{ }^{\circ} \mathrm{C}$. As the solution is discharged from the pot and cooled, the salt is allowed to precipitate to form a salt cake at the bottom of the receipt tank. A schematic of the evaporator pot is shown in Figure 1.

Evaporation in the pot is accomplished with a steam tube bundle submerged just below the liquid level in the center of the evaporator pot. The heating coils are bayonet type, permitting flexing as the coil temperature changes. A thermal shocking sequence is used periodically during operation to assist in desalting and descaling the bundle. As the water is evaporated, the salt solution is concentrated. This dense concentrate is gravity segmented to the bottom of the pot. The concentrated solution is discharged from the bottom of the cone using a lift line. Unlike a normal eductor, the lift works when either steam or air is fed into the line to create a reduced density zone that is pushed out of the evaporator pot by the head pressure in the vessel.

The conical portion of the evaporator pot contains 25-psig steam-warming coils used to maintain the waste temperature during shutdown and to heat the contents during a cleaning operation. The warming coils are fixed and have no descaling capability.

\subsection{EVAPORATION PROCESS}

The $2 \mathrm{H}$ evaporation process consists of Tank $43 \mathrm{H}$, the dilute waste feed tank to the $2 \mathrm{H}$ evaporator, and Tanks $38 \mathrm{H}$ and $41 \mathrm{H}$, used for concentrate receipt. During historic processing, the waste was typically concentrated by $30-40$ volume percent. ${ }^{1,2},{ }^{3}$ However, since receipt of recycle waste solutions from the Defense Waste Processing Facility (DWPF) which began in 1995, concentration has at times approached 90 volume percent.

The evaporation process is used to maximize removal of water and decrease the original volume as much as possible. This is accomplished by recycling from the receipt tank $38 \mathrm{H}$ back to the feed tank $43 \mathrm{H}$. As a result of recycling and dilute DWPF feed, a concentration gradient can be established in Tank 43. The actual feed to the evaporator will depend on the concentration gradient, agitation and feed level, and location. A diagram of the evaporator system is shown in Figure 2. 


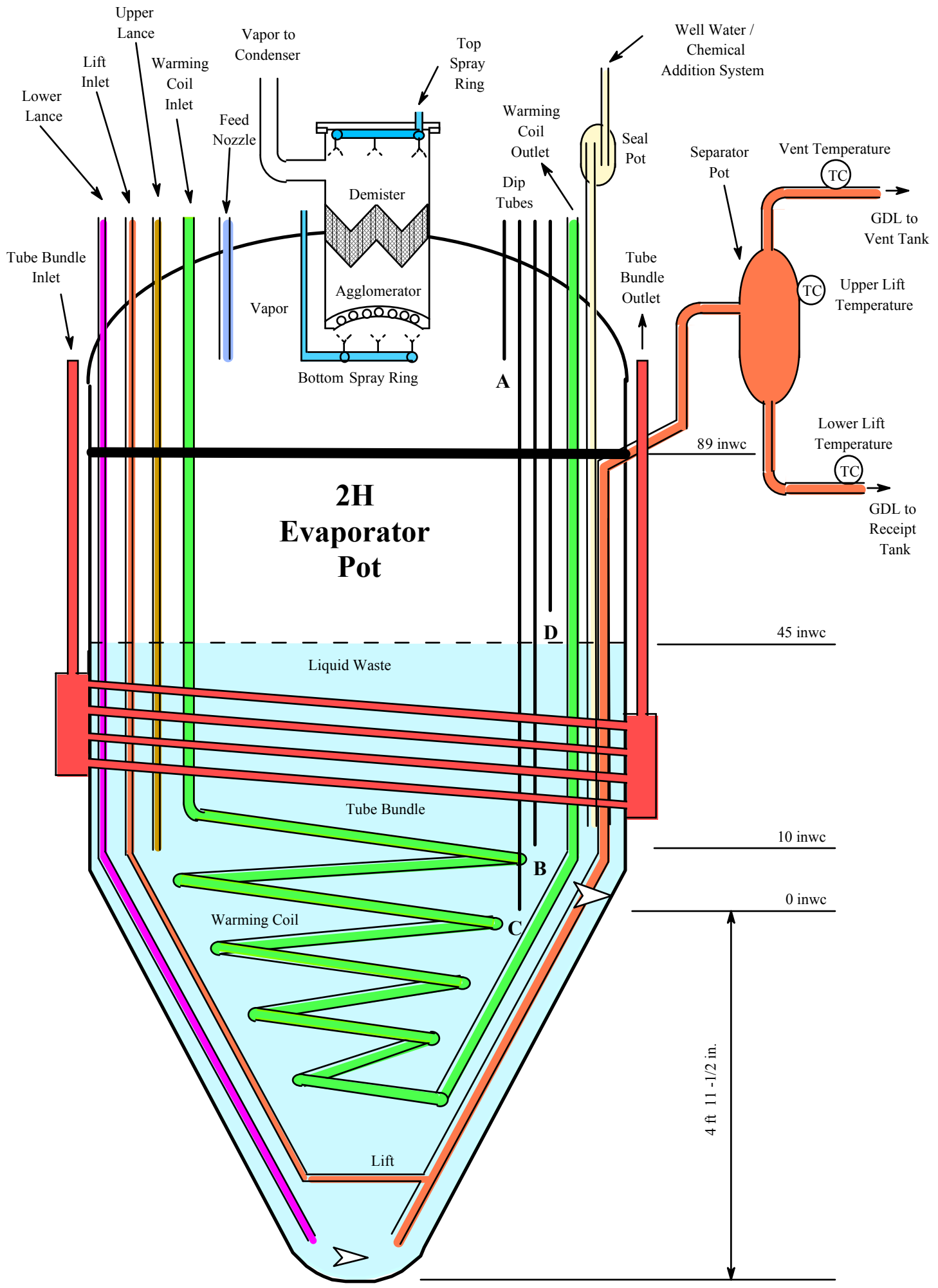

Figure 1. 2H Evaporator Pot Diagram

Page 2 of 44 


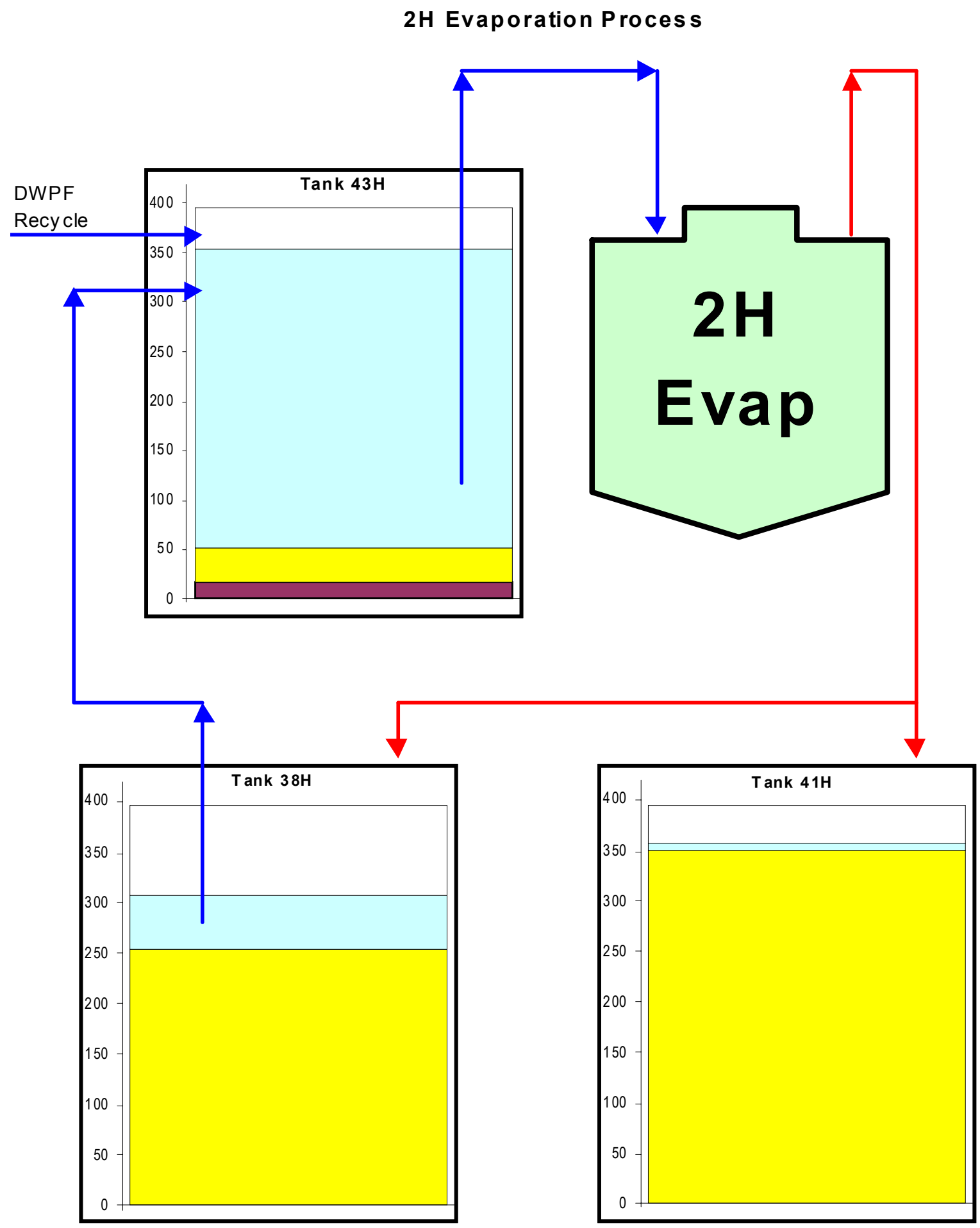

D:lapplEv ap ITankTarml[Tanks -LOD.xls]2H Operations

Figure 2. 2H Evaporator System Schematic 


\subsection{EVAPORATOR SCALING}

In July 1997, difficulty in maintaining lift flow in the Gravity Discharge Line (GDL) occurred. A video inspection of the line indicated the presence of solid deposits in the GDL. Analysis identified the solids as a sodium aluminosilicate of the general formula $\mathrm{Na}_{8} \mathrm{Al}_{6} \mathrm{Si}_{6} \mathrm{O}_{24}\left(\mathrm{NO}_{3}\right)_{2} \bullet 4 \mathrm{H}_{2} \mathrm{O}{ }^{1}$

The evaporator was in operation again from July 1997 until June 1998. Operational difficulty was again experienced and the GDL was cleaned via water jetting. Operation again resumed until 1999, at which time a planned video inspection revealed significant accumulation in the evaporator pot. Because of the build-up of deposits in the evaporator, a Potential Inadequacy in the Safety Analysis (PISA) was issued. This declaration was in large part due to the inventory of enriched uranium contained in the evaporator deposits. Photos show the evaporator before (Figure 3) and after (Figure 4) the most recent cleaning.

\subsection{OBJECTIVES OF WORK}

This study was designed to provide insight into the deposition process on the $2 \mathrm{H}$ evaporator. Experiments were designed to evaluate various parameters on the tendency to form the tenaciously adherent deposits on stainless steel substrate. These laboratory studies were performed using small volumes of reagents and stainless steel beakers as deposition chambers to represent the evaporator surface. The tests were purposefully designed to use a highly supersaturated feed solution $0.1 \mathrm{M} \mathrm{Si}, 0.1 \mathrm{M} \mathrm{Al}, 6 \mathrm{M}$ Sodium, $1 \mathrm{M}$ nitrate, $1 \mathrm{M}$ nitrite, and $4 \mathrm{M}$ free hydroxide previously developed by L. O. Dworjanyn and ORNL. This simulant was used because these high concentrations allow production of measurable quantities of aluminosilicate at a temperature of $80^{\circ} \mathrm{C}$ in the time frame of only hours.

Two categories of testing were performed. The initial testing was batch testing. The second round of testing was of a continuous feed nature, introducing fresh feed throughout the reaction.

The primary parameters of investigation for batch phase of this work were as follows:

- Effects of mixing on aluminosilicate deposition

- Effects of aging the simulated feed solutions on deposition

- Combined effects of aging and mixing on deposition

The primary parameters of investigation for the continuous feed phase of this work were as follows:

- Effect of mixing on aluminosilicate deposition

- Effect of seeding on aluminosilicate deposition

Page 4 of 44 


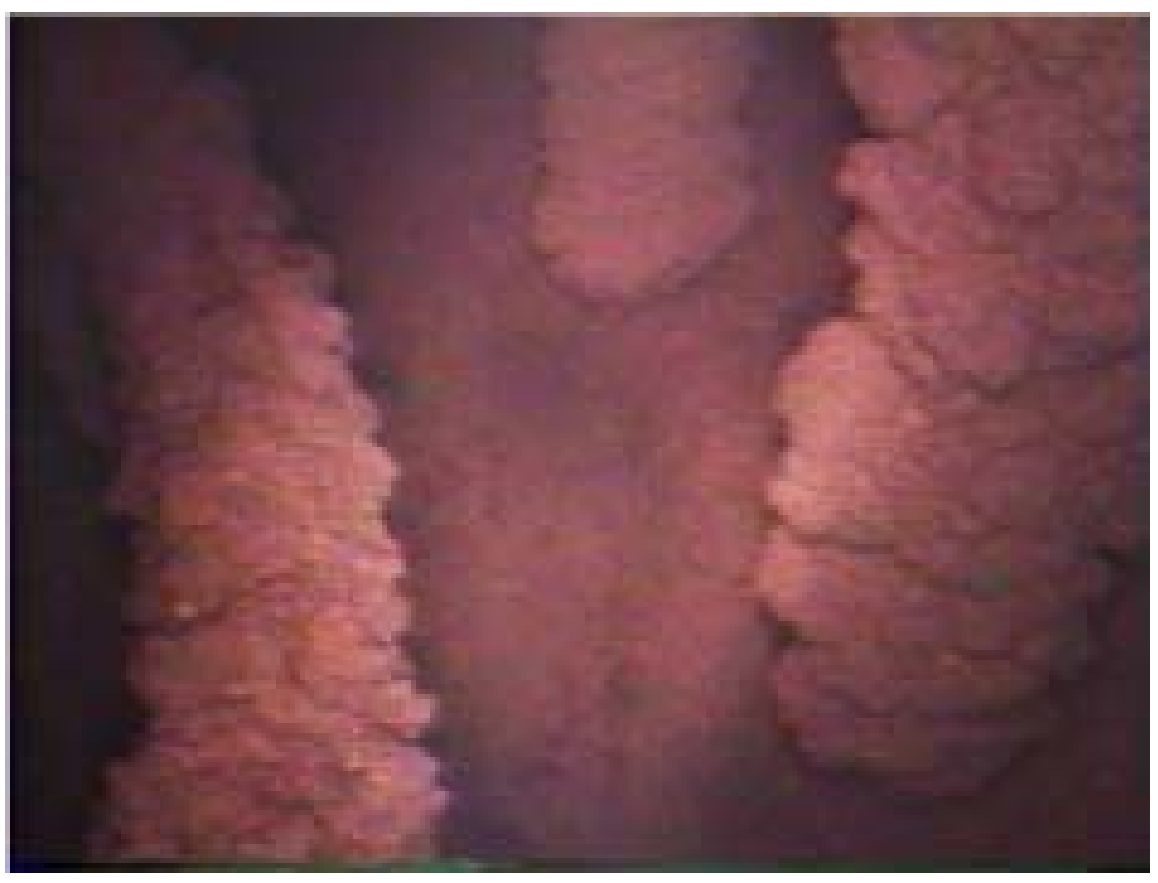

Figure 3. $2 \mathrm{H}$ Evaporator on 4/30/01 before cleaning

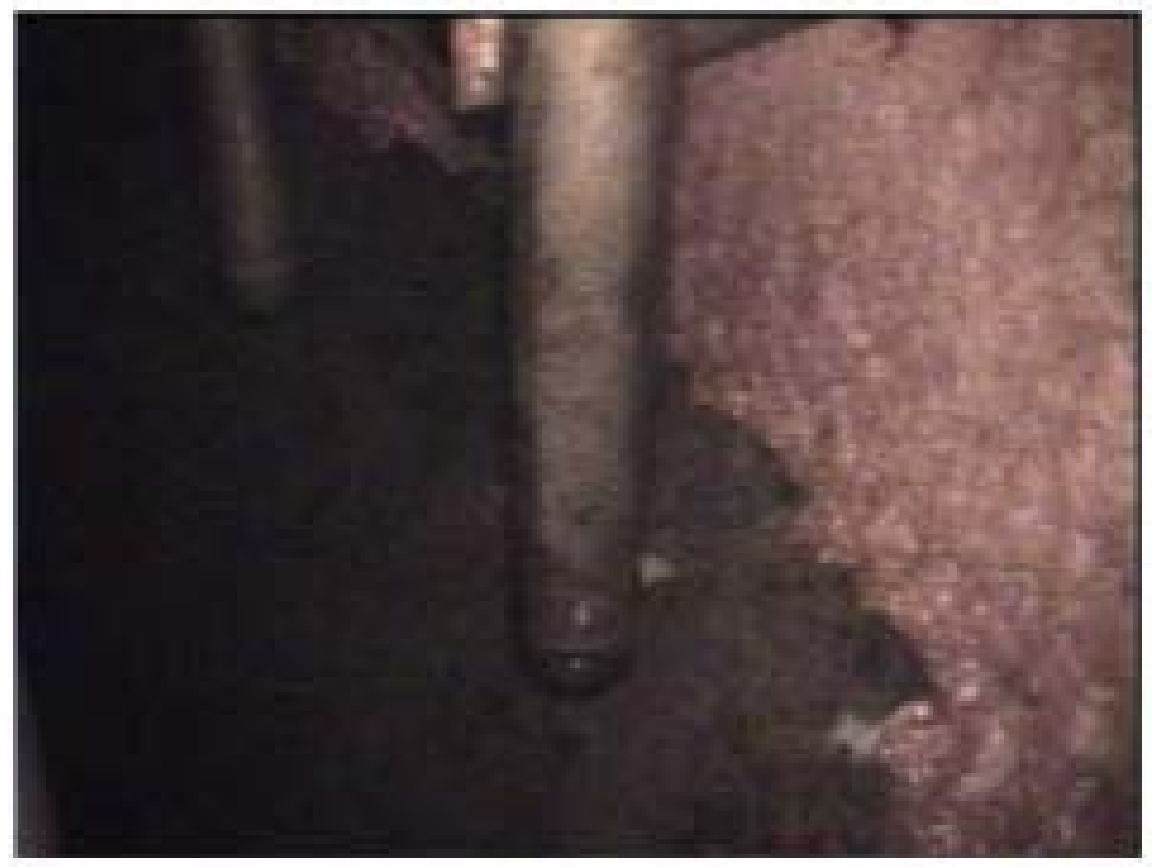

Figure 4. 2H Evaporator on 6/7/01 after cleaning. 
This page intentionally left blank.

Page 6 of 44 
WSRC-TR-2001-00464, REVISION 0

\subsection{EXPERIMENTAL}

\subsection{PREPARATION OF SILICON SOLUTION}

Frit is used in DWPF to form glass in mixtures and is rich in silicon. Frit solution for testing was prepared by boiling 20 grams of frit 200 in a solution containing $800 \mathrm{ml}$ of de-ionized water and 160 grams of sodium hydroxide. Boiling continued in a 1200-milliliter stainless steel beaker for twenty hours. A Teflon stirring bar was used to disperse the frit. The resulting solution was cooled and filtered through a Whatman No. 1 paper filter into a Nalgene storage bottle. A $5 \mathrm{ml}$ aliquot of the solution was sent to Analytical Development Section (ADS) for Inductively Coupled Plasma-Emission Spectroscopy (ICP-ES) analysis for silicon. Based on this analysis the solution was diluted to $4 \mathrm{M}$ free hydroxide for a final concentration of $0.2 \mathrm{M}$ soluble silicon.

\subsection{PREPARATION OF ALUMINUM SOLUTION}

Simulated aluminum-rich solution was formulated by first dissolving 160 grams of sodium hydroxide pellets per liter of de-ionized water. Once the solution cooled to room temperature, 100 grams per liter of aluminum nitrate was added and dissolved. Following complete dissolution of the aluminum salt, 170 grams per liter of sodium nitrate crystals were dissolved. A final addition of 138 grams per liter of sodium nitrite was added and the solution brought to volume using de-ionized water. The resulting solution was transferred to a Nalgene storage bottle.

\subsection{PREPARATION OF THE SIMULATED EVAPORATOR FEED}

In order to form a simulated evaporator feed that demonstrated a well-characterized reaction profile, the silicon-rich and aluminum-rich solutions (Figure 5) are not mixed until the experiment is initiated. The above solutions are formulated in a manner such that when equal volumes of the two solutions are mixed the resulting solution has final concentrations of $0.1 \mathrm{M}$ Silicon, $0.1 \mathrm{M}$ Aluminum, $4 \mathrm{M}$ hydroxide, $6 \mathrm{M}$ sodium, $1 \mathrm{M}$ nitrate, and $1 \mathrm{M}$ nitrite. This mixture is the simulated evaporator feed solution used in the experiments described in this report.

\subsection{BATCH TESTING METHODOLOGY}

Batch aluminosilicate deposition tests were conducted using the above formulation for simulated evaporator feed. These tests were performed on a $200 \mathrm{~mL}$ scale at $80{ }^{\circ} \mathrm{C}$ using the apparatus displayed in Figure 6. A water bath was used to provide a constant reaction temperature for the stainless steel beaker that served as the reaction/deposition chamber. The total time in the stainless steel beaker was 2 hours. A new stainless steel beaker was used for each experiment and was pre-weighed prior to starting of the experiment. The beaker was covered during each run to ensure that the liquid volume was maintained and that evaporation was negligible. 


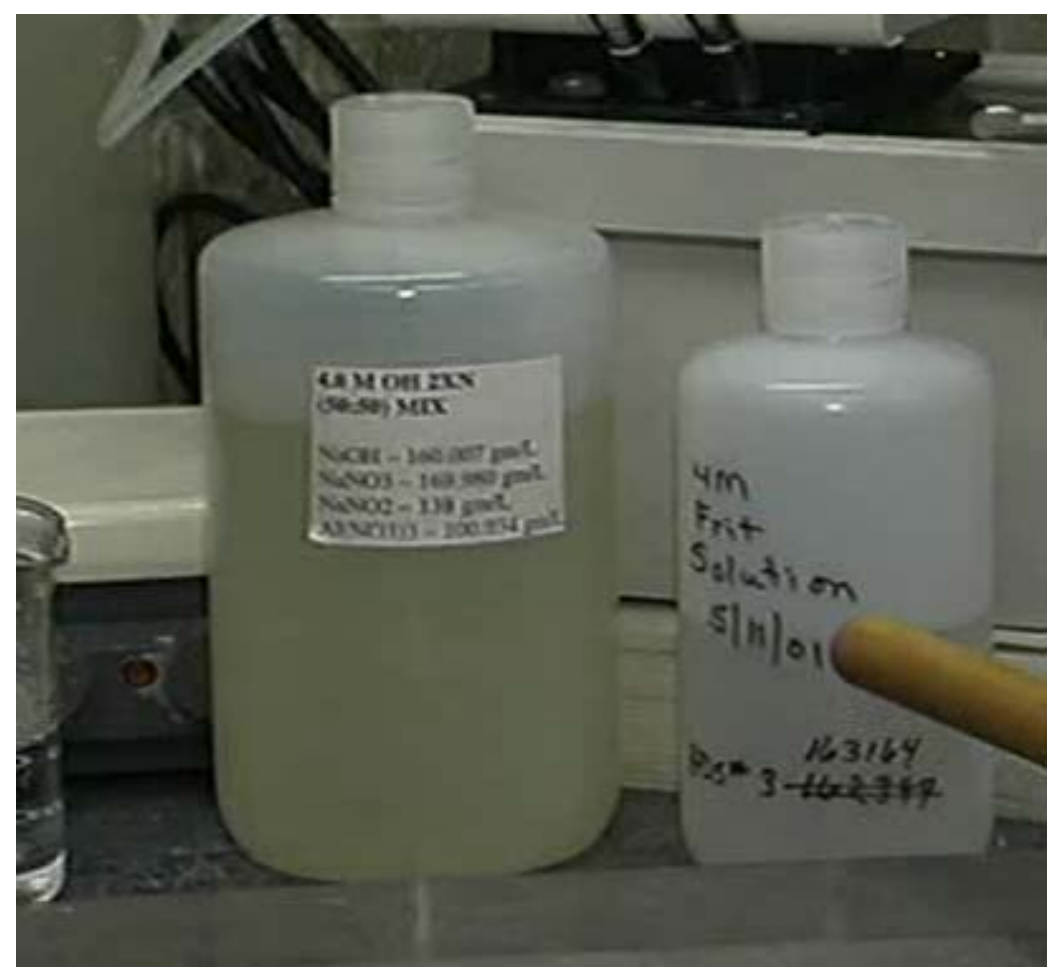

Figure 5. Left bottle - Aluminum solution (Section 2.1); Right bottle - Silicon-rich solution (Section 2.2).

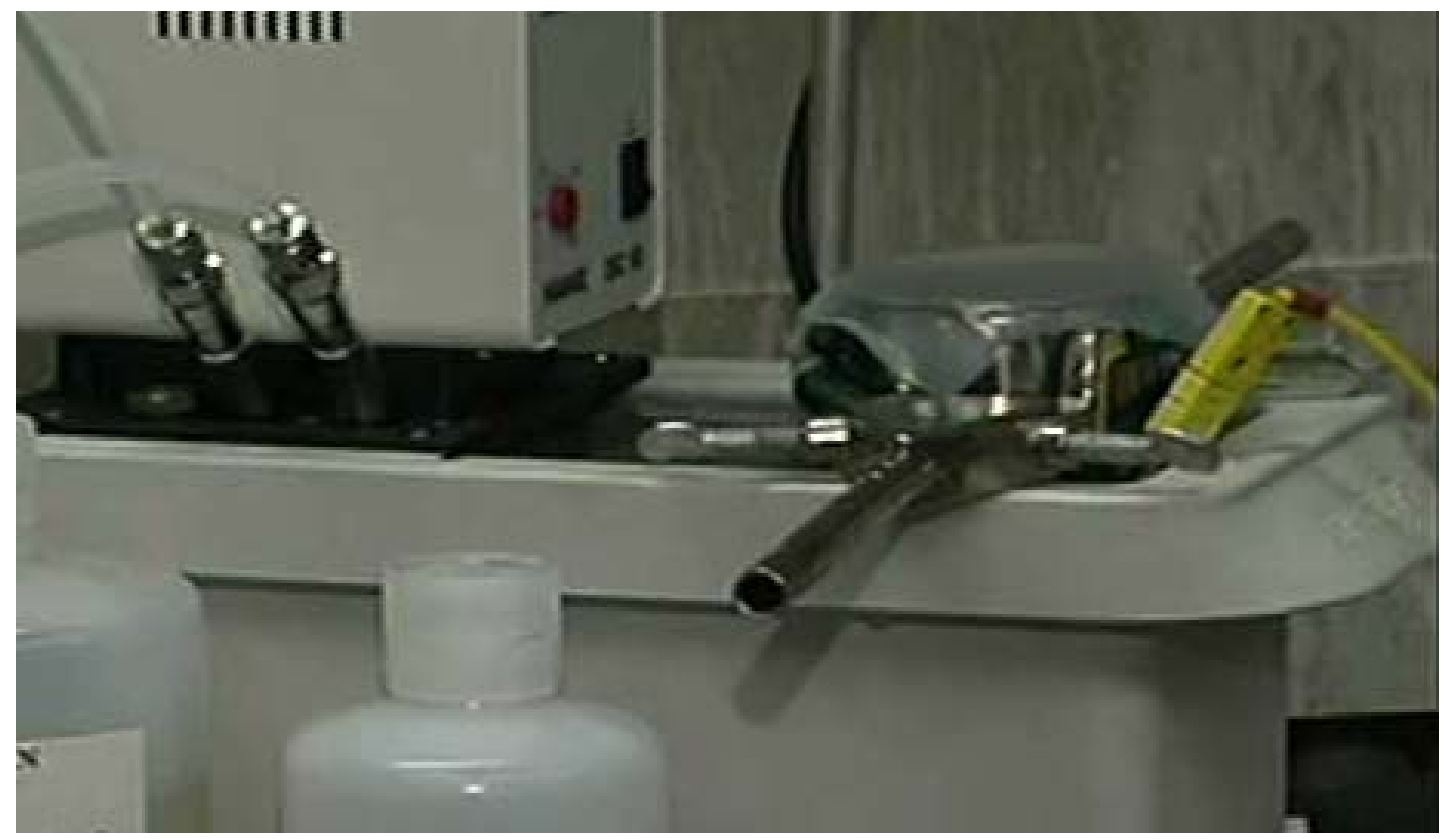

Figure 6. Batch testing apparatus consisting of stainless steel beaker immersed in water bath at $80^{\circ} \mathrm{C}$. 
In this phase of the work, the primary scenarios evaluated were the effects of mixing and aging on the deposition with each condition being run in triplicate. Two response variables were measured:

- the amount of solids adhered to the vessel as a deposit

- the amount of loose solids in solution

Three mixing conditions were evaluated - unmixed, low mixing, and high mixing. The lowmixing condition utilized $90 \mathrm{rpm}$ that corresponds to an energy dissipation rate of $<0.2 \mathrm{~W} / \mathrm{kg}$ of solution. The high-mixing condition was $250 \mathrm{rpm}$ that corresponds to an energy dissipation rate of $0.4-0.8 \mathrm{~W} / \mathrm{kg}$ of solution.

The aging or "preformed" tests were designed to simulate the reaction of any supersaturated silicon and aluminum in the feed tank prior to entry into the evaporator system. To simulate this in these deposition experiments, the reactive evaporator feed solution was prepared and placed in a polyethylene container at $80{ }^{\circ} \mathrm{C}$ for varying amounts of time. Aluminosilicate solids were formed, but did not adhere to the polymeric container. The resulting slurry was then transferred into the stainless steel beaker and the regular 2-hour deposition test at $80{ }^{\circ} \mathrm{C}$ was performed in an unmixed configuration. The times of pre-formation were 2,4 , and 8 hours. One final preform test of 8 hours was performed, then the resulting 2-hour deposition period in the stainless steel vessel was carried out under the high mixing condition. This set of tests was designed to evaluate the dual effects of mixing and aging.

At the end of the two-hour reaction period in the stainless steel beaker, the solution was collected and filtered to characterize the mass of solids that remained in the bulk solution and did not adhere. The beaker was rinsed several times with de-ionized water to assist in removal of loosely adhered solids. Both the filtered solids and the deposited solids on the internal surfaces of the vessel were dried and weighed. Filtration occurred through a Whatman \#42 filter and the samples were dried at $105^{\circ} \mathrm{C}$ until constant weight (4hours). Samples of both solids were sent for characterization including but not limited to $\mathrm{x}$-ray diffraction and scanning electron microscopy.

\subsection{CONTINUOUS TESTING METHODOLOGY}

Continuous aluminosilicate deposition tests were conducted using the above formulation for simulated evaporator feed. These tests were performed on a nominal $200 \mathrm{~mL}$ scale at $80{ }^{\circ} \mathrm{C}$ for three residence times given a fixed feed rate into the simulated evaporator (Figure 7). The reaction vessel included an overflow system to remove excess solution. The overflow consisted of a stainless steel "T" that was welded to the wall of the vessel to allow for effluent to be drawn from under the surface. For this phase of the work, the primary scenarios evaluated were the effects of mixing and seeding on the deposition with each condition being run in triplicate. Two response variables were measured - the amount of solids adhered to vessel as a deposit and amount of solids suspended in solution and passed through the vessel. 


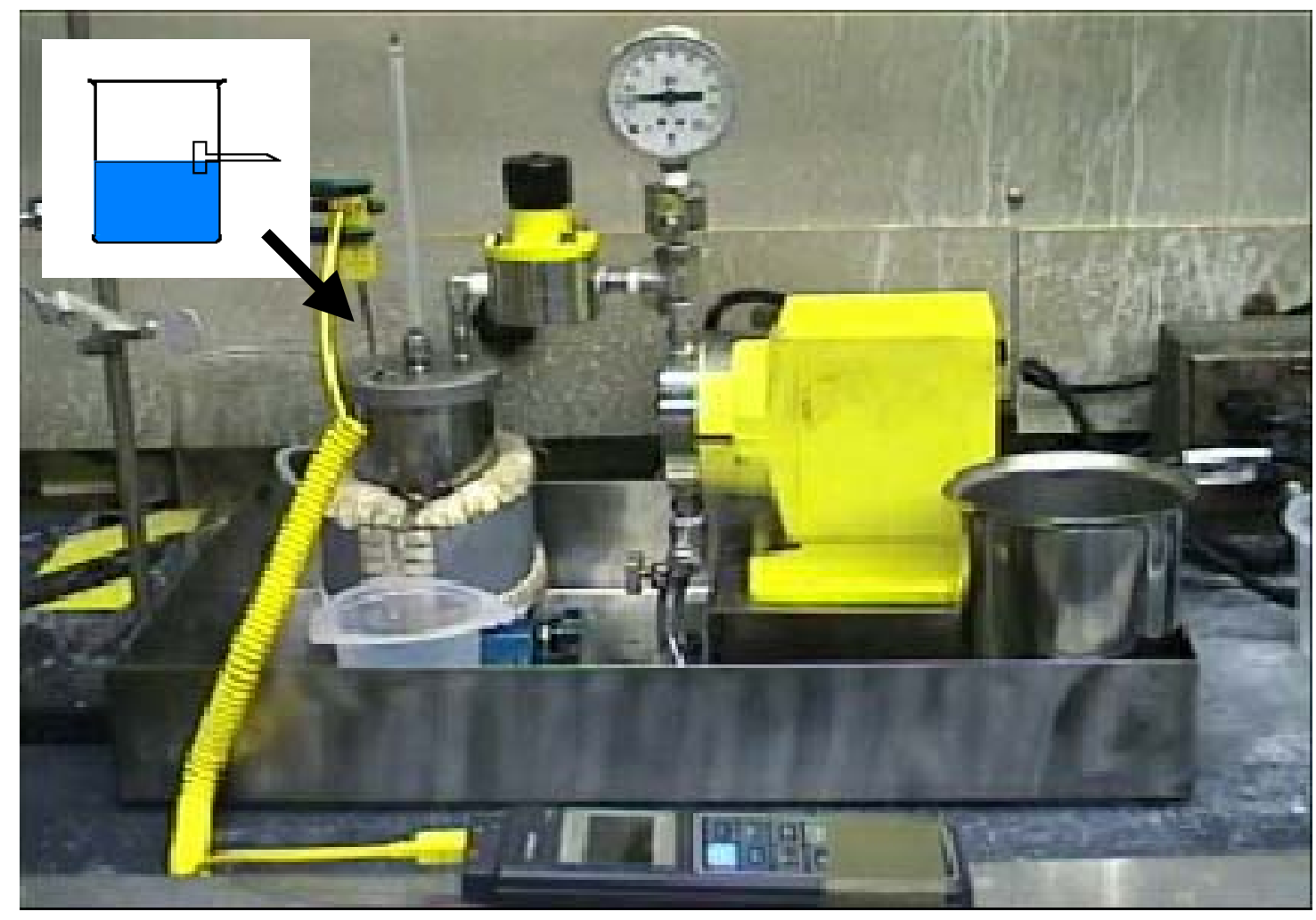

Figure 7. Continuous deposition testing apparatus

Three mixing conditions were evaluated - unmixed, low mixing, and high mixing. The lowmixing condition utilized $90 \mathrm{rpm}$ that corresponds to an energy dissipation rate of $<0.2 \mathrm{~W} / \mathrm{kg}$ of solution. The high-mixing condition was $250 \mathrm{rpm}$ that corresponds to an energy dissipation rate of $0.4-0.8 \mathrm{~W} / \mathrm{kg}$ of solution.

The seeds used for the seeding experiments were supplied by Mattus from ORNL. In order to ensure continuity for the seeding tests performed at both SRS and ORNL, the seeds were from the same lot used in the ORNL testing. The seed material was a natural zeolite by the name of chabazite and the details of the physical and chemical properties of this material can be found in the Mattus report. $2,3,4,5$.

The seed level used for this work was an equivalent of $5 \mathrm{~g} / \mathrm{L}$. Because our reactor has a nominal volume of $200 \mathrm{ml}$ and the experiment is operated for three reactor turnover periods, this resulted in 3 grams of the seed material per experiment. A continual addition of this amount of seed over the course of the six-hour experiment was not practical, thus the seeds were added in 0.25 -gram increments every 30 minutes beginning at time zero. The seeds were slurried up in about $1-2 \mathrm{ml}$ of $4 \mathrm{M}$ caustic and pippetted into the reactor. The mixing was set at $250 \mathrm{rpm}$. 
The initial reactor volume consisted of $4 \mathrm{M}$-sodium hydroxide containing $1 \mathrm{M}$ each of sodium nitrate and sodium nitrite. The system was heated up to $80^{\circ} \mathrm{C}$ using an electrothermal digital temperature controller. This controller is capable of maintaining the temperature within one degree according to the manufacturer.

The pump was a diaphragm apparatus that can deliver as little as $0.8 \mathrm{ml} / \mathrm{min}$. The deposition chamber was modified stainless steel beaker. The $200 \mathrm{ml}$ case was examined for this initial phase of work because this allows for a more direct comparison with the batch deposition testing that was performed under essentially the same conditions with the notable exception of not having continuous fresh feed.

Larger holdup volumes will be considered in future phases of the work. The advantage of the larger holdup volume is that it will allow for longer residence times to be examined while maintaining accuracy on the pumps deliver rate. If the holdup volume is too small and the desired residence time is too long then operationally the experiment can not be performed because of a lower limit on the pump delivery rate.

Samples of the overflow were taken at 15, 30, 45, 60, 90, 120, 180, 240, 300,and 360 minutes. The $5 \mathrm{ml}$ samples were filtered through a 0.2 -micron nylon filter prior to being analyzed for silicon, aluminum, and sodium. The remaining overflow solution was retained and filtered to determine the amount of solids that pass through in the overflow stream. The volume of the overflow was recorded at the same intervals as the samples were taken.

A typical experiment ran three turnovers with the constant variable in each experimental grouping being the total reaction time. The solution to fill the feed reservoir was mixed at ambient temperature and then transferred to the feed reservoir. A sample of this feed was taken at the beginning and end of the experiment and filtered through 0.2-micron nylon filters. The ICP-ES analysis for silicon and aluminum conclusively demonstrated there was no decrease in the concentration of these elements over the course of the experiment. In other words, reaction did not occur in the feed reservoir.

The pump was primed prior to assembly of the reaction chamber to ensure a minimal delay in feed transfer once the chamber comes to a stabilized reaction temperature. The actual recording of the time of starting transfer occurred at the first sign of overflow. This inception of overflow marked the time zero for the experiment.

Excess solution was discharged through the overflow system. Effluent solution was collected and filtered to characterize the mass of solids that passed through the vessel. Filtrate samples were analyzed for $\mathrm{Si}, \mathrm{Na}$, and $\mathrm{Al}$ using ICP-ES. The beaker was rinsed several times with de-ionized water to assist in removal of loosely adhered solids. Both the filtered solids and the deposited solids on the internal surfaces of the vessel were dried and weighed. Filtration occurred through a Whatman \#42 filter and the samples were dried at $105^{\circ} \mathrm{C}$ until constant weight (4hours). Samples of both solids were sent for characterization, including but not limited to x-ray diffraction and scanning electron microscopy. 
This page intentionally left blank.

Page 12 of 44 
WSRC-TR-2001-00464, REVISION 0

\subsection{RESULTS AND DISCUSSION}

\subsection{BATCH DEPOSITION TESTING}

Aluminosilicate deposition testing was performed according to the methodology discussed in Section 2.4. The conditions evaluated were no mixing, low mixing, and high mixing, as well as a series of pre-formation or aging tests to evaluate the effect of age on the deposition propensity for aluminosilicate solids on the stainless steel surfaces employed in our study.

As previously discussed, each experimental configuration was run in triplicate and the resulting precision is stated at the $80^{\text {th }}$ percentile of confidence. At the end of each two-hour reaction period in the stainless steel beaker, the solution was collected and filtered to characterize the mass of solids that passed through the vessel and did not adhere. The beaker was rinsed several times with de-ionized water to assist in removal of loosely adhered solids. Both the filtered solids and the deposited solids on the internal surfaces of the vessel were dried and weighed. Selected samples of both solids were sent for characterization including but not limited to x-ray diffraction and scanning electron microscopy. A deposition coefficient was determined by looking at the percentage of the total solids formed that adhered to the stainless steel beaker. The deposition coefficient is defined as the fraction of the total solids formed that adhered to the stainless steel beaker. Realizing that the total solids formed are the combined masses of the solids adhered to the beaker and the mass of the unattached solids that were collected via filtration and dried.

\subsubsection{Unmixed Deposition Testing}

For the unmixed or quiescent testing sequence, the $200 \mathrm{ml}$ of supersaturated simulated evaporator feed solutions were preheated to $80{ }^{\circ} \mathrm{C}$ individually, then mixed (swirling for 15 seconds) in the reaction chamber to denote the start of the experiment.

The solids present in the filtrate as well as the solids adhered to the stainless steel vessel were dried and weighed after the 2 -hour reaction time. The mean of the triplicate measurements of deposition coefficients was $65 \%$ with an $80 \%$ confidence interval of $+/-11 \%$.

The resulting deposition occurred predominately on the bottom of the deposition chamber. This likely is the result of material being produced and growing to a critical size at which time the probability of remaining suspended decreases and the particles accumulate on the bottom of the reaction chamber. Apparently, because a supersaturated condition persists, these settled particles are fused and tenaciously adhere to the vessel surfaces. Some minimal deposition is observed on the walls of the beaker also. The most likely sequence of steps to lead to the observed pattern is a combination of homogeneous formation which is facilitated by the relatively high supersaturation in tandem with the formation of a heterogeneously formed film at the stainless steel/evaporator liquor interface. Particles formed in the bulk appear to deposit on the vertical surfaces as well but with a decreased tendency. A photograph of the vessel at the end of the reaction period is shown in Figure 8.

Page 13 of 44 


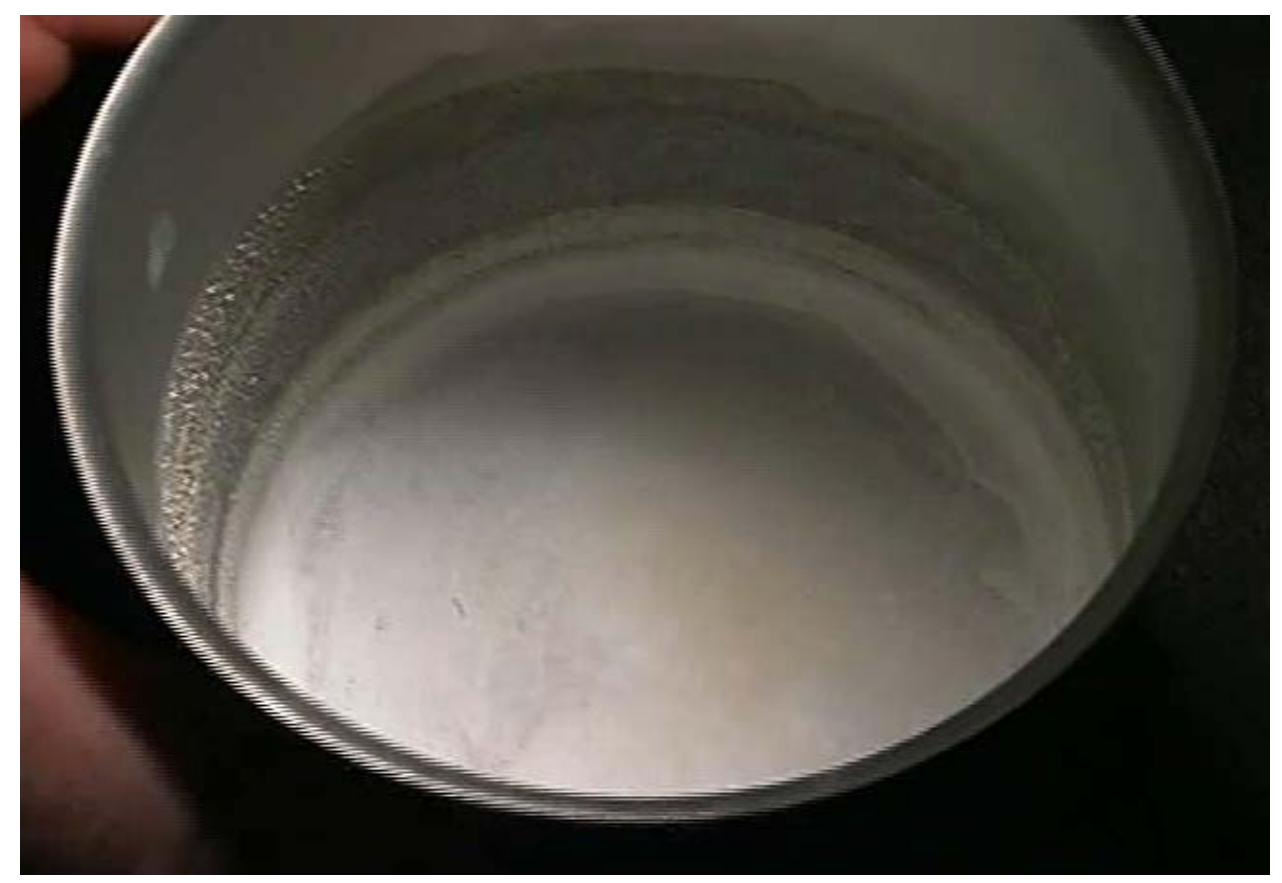

Figure 8. Stainless steel beaker after reaction for the unmixed batch test

Selected samples of both the filtrate and deposited solids were submitted for X-ray diffraction and scanning electron microscopy. X-ray diffraction supports the previous finding of our research. Namely, that a sodium aluminosilicate is responsible for the primary reflection in the pattern. X-ray diffraction spectra were examined from various locations of solids in the beaker as well as the filtrate and showed essentially the same spectrum. An x-ray diffraction from the solids scraped from the deposition chamber is shown in Figure 9 and an $x$-ray diffraction spectrum for the solids not adhered to the stainless steel, but rather suspend in the bulk of the liquor is shown in Figure 10.

Scanning electron microscopy analyses clearly show that the dominant structures produced are spherical yarn-ball like which have previously been reported ${ }^{2,3,4}$. Upon further inspection one finds that these spherical solids are composed of rod-like crystals which appear to have agglomerated. Scanning electron microscopy for the solids adhered to the beaker is shown in Figure 11. Scanning electron microscopy for the solids remaining suspended in the bulk liquor is shown in Figure 12. The solids apparently have very similar microstructure regardless of their location in the experimental system. It is interesting to note that the cubic zeolitic structures are occasionally observed. This is thought to be the result of the relatively short reaction time and the $80{ }^{\circ} \mathrm{C}$-reaction temperature and has also been reported by DePaoli and co-workers at ORNL. 


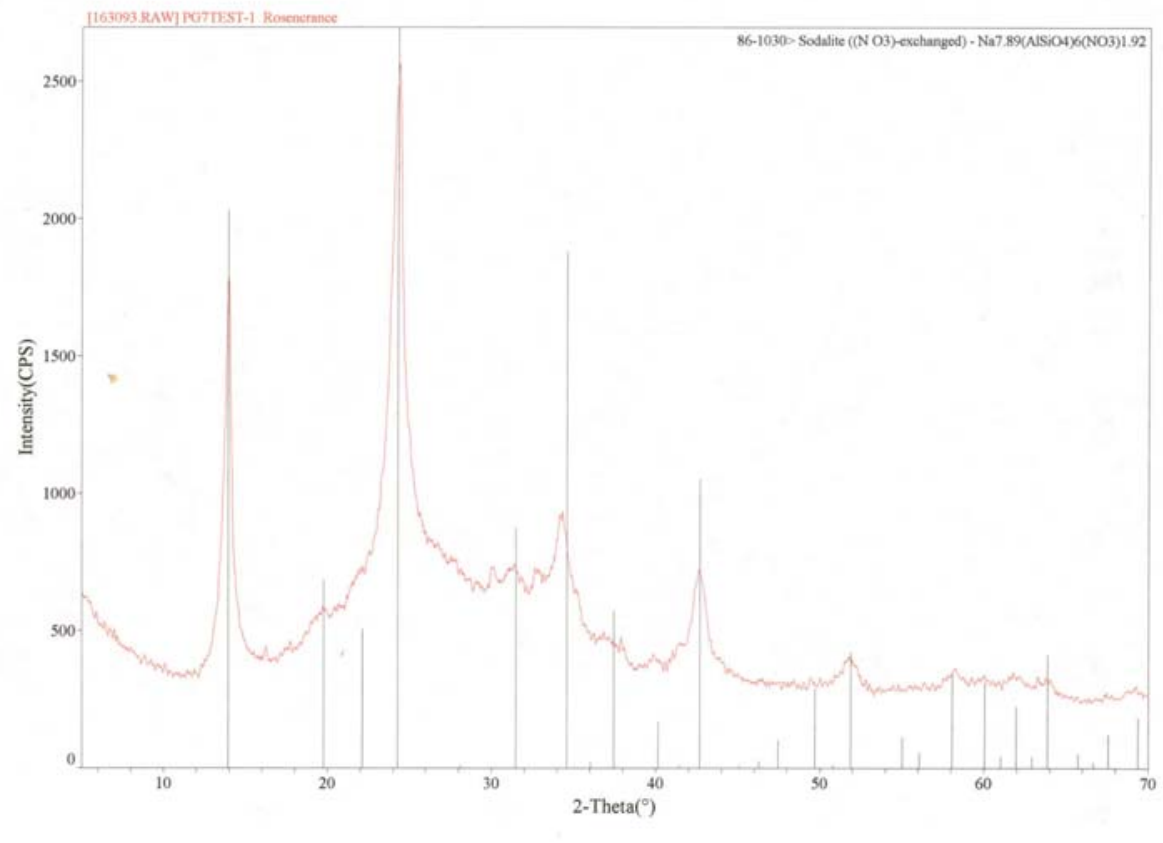

Figure 9. X-ray diffraction for deposited solids from unmixed batch test

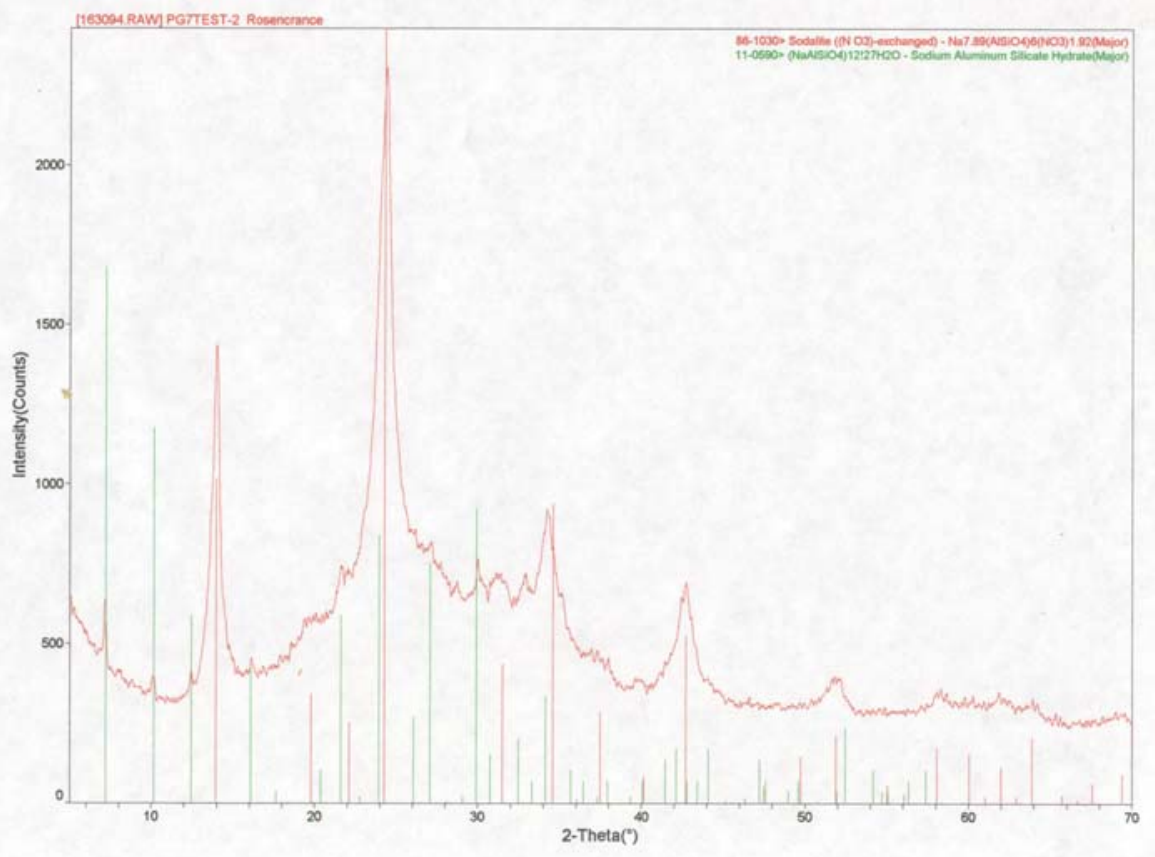

Figure 10. X-ray diffraction for non-deposited solids from unmixed batch test

Page 15 of 44 


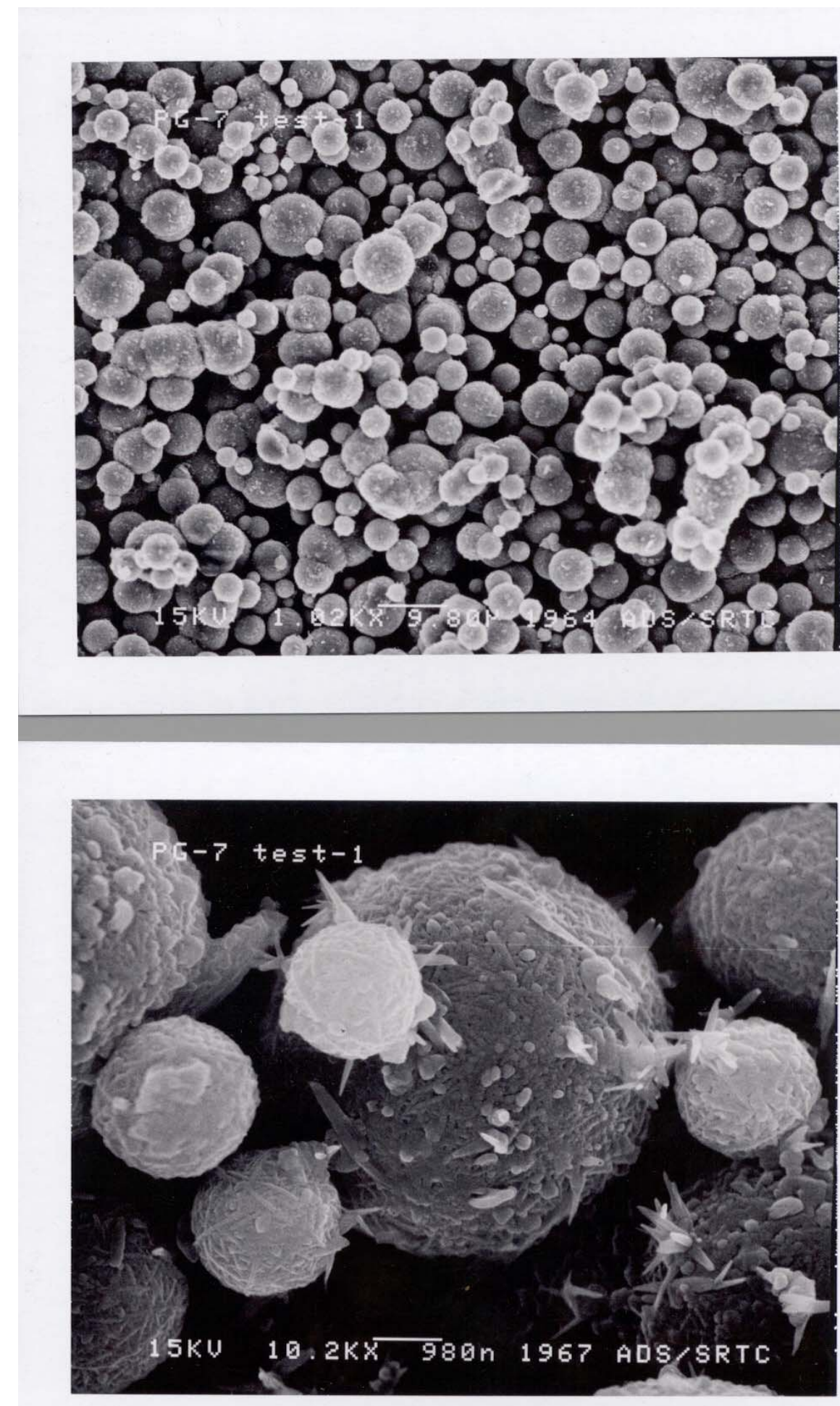

Figure 11. Scanning electron microscopy of deposited solids from unmixed batch test. Note: Bottom view is magnified 10X relative to top photo. 

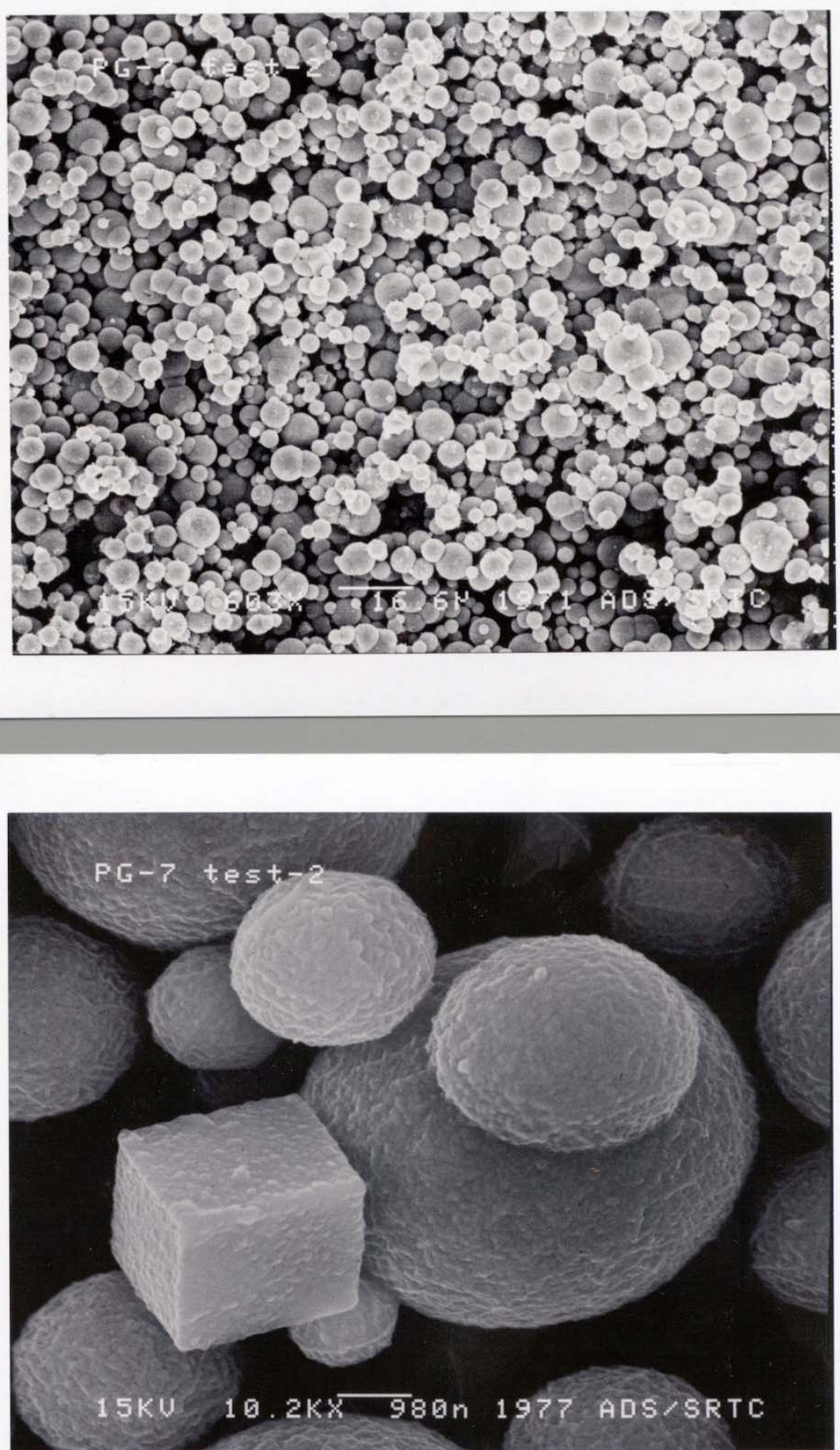

Figure 12. Scanning electron microscopy of non-deposited solids from unmixed batch test.

Note: Bottom view is magnified 20X relative to top photo. 


\subsubsection{Low Mixing Deposition Testing}

For the low mixing testing sequence, the $200 \mathrm{ml}$ of supersaturated simulated evaporator feed solutions were preheated to $80{ }^{\circ} \mathrm{C}$ individually, then mixed in the reaction chamber to denote the start of the experiment. A polyethylene stir shaft (Figure 13) was used to mix the solution during the entire reaction period. The stir rate was $90 \mathrm{rpm}$, which was calculated to have an overall energy dissipation rate of $<0.2 \mathrm{~W} / \mathrm{kg}$ of solution. The energy dissipation rate was obtained by measuring the power output (Watts) necessary to stir at the prescribed RPM, in this case 90 , for a $262 \mathrm{~g}(200 \mathrm{ml})$ sample of the liquor. The energy dissipation was reported on a $\mathrm{kg}$ basis via normalization.

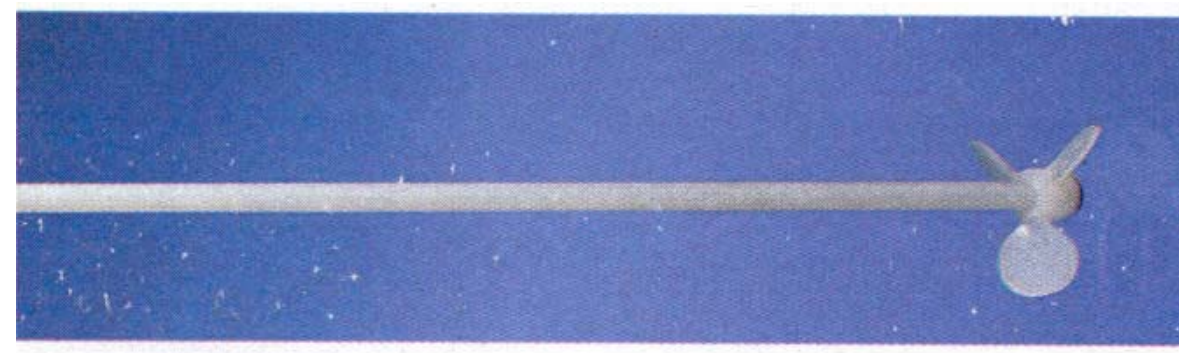

\section{Nalgene Polyethylene Stirrer Shaft with Blades}

High-density polyethylene stirrer with steel insert. Blade diameter, $13 / 4^{\prime \prime}$ $(44 \mathrm{~mm})$. Rod, $1 / 4$ O.D. $\times 18^{\prime \prime}$ long $(6.4 \times 457 \mathrm{~mm})$. Rod may be cut to any length with hacksaw.

\section{Figure 13. Polyethylene stir shaft used for mixing}

The solids present in the filtrate as well as the solids adhered to the stainless steel vessel were dried and weighed. The mean of the triplicate measurements of deposition coefficient was $49 \%$ with an $80 \%$ confidence interval of $+/-17 \%$.

The resulting deposition occurred predominately on the bottom of the chamber. The sides of the beaker appear to have less deposit than the previously discussed unmixed series of tests. The deposits on the vertical walls of the vessel during the low mixing series are relatively few and appear as spikes or shark's teeth. Perhaps the major observation of the deposited solids is in reference to the obvious structure contained in the deposits on the bottom of the vessel. Immediately below the axial downflow impeller is an approximately circular clean spot where few deposits are observed. Moving radially to the outside of the vessel complex clockwise swirling patterns are observed. Figure 14 shows the stainless steel beaker following the reaction period. 


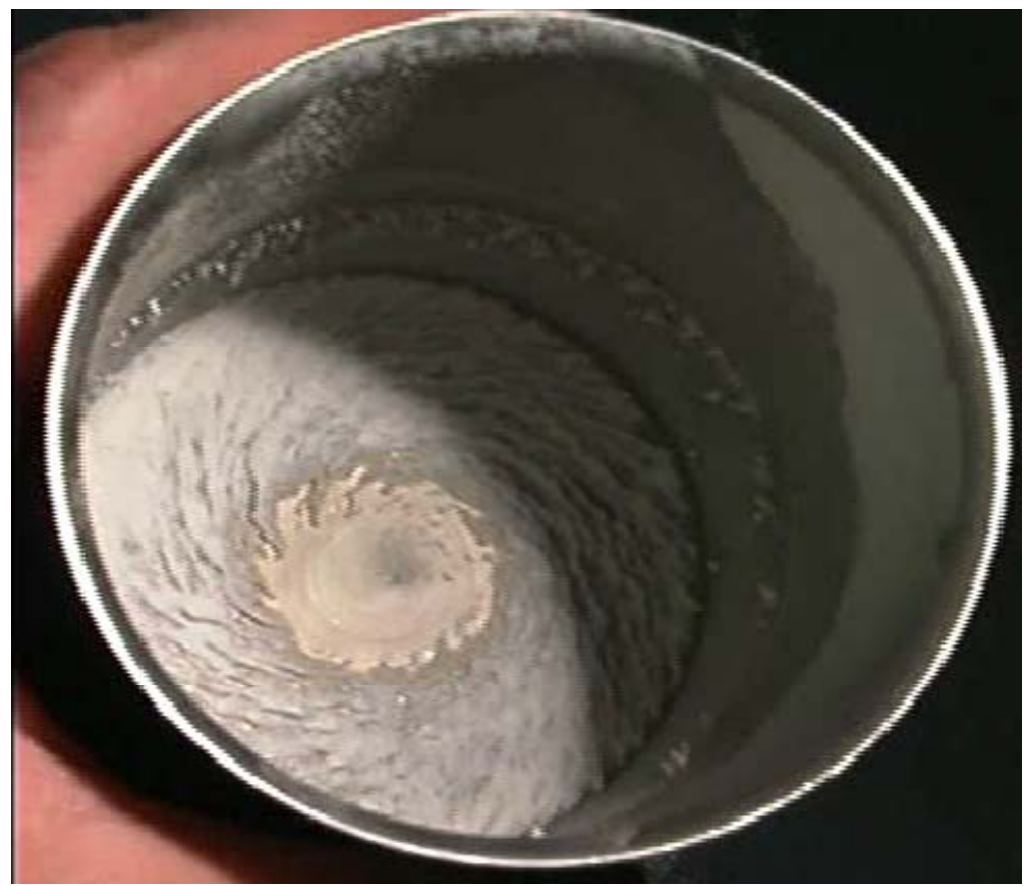

Figure 14. Stainless steel beaker after reaction for the low mixing batch test

\subsubsection{High Mixing Deposition Testing}

For the high mixing testing sequence, the $200 \mathrm{ml}$ of supersaturated simulated evaporator feed solutions were preheated to $80^{\circ} \mathrm{C}$ individually, then mixed in the reaction chamber to denote the start of the experiment. A polyethylene stir shaft (Figure 13) was used to mix the solution during the entire reaction period. The stir rate was $250 \mathrm{rpm}$, which was calculated to have an overall energy dissipation rate of $0.4-0.8 \mathrm{~W} / \mathrm{kg}$ of solution.

The solids present in the filtrate as well as the solids adhered to the stainless steel vessel were dried and weighed. The mean of the triplicate measurements of deposition coefficient was $15 \%$ with an $80 \%$ confidence interval of $+/-3 \%$.

The resulting deposition was dramatically decreased under the high mixing conditions. The resulting deposits were essentially uniformly distributed throughout the stainless steel beaker. Figure 15 shows an image of the stainless steel beaker after undergoing deposition in the high mixing condition. 


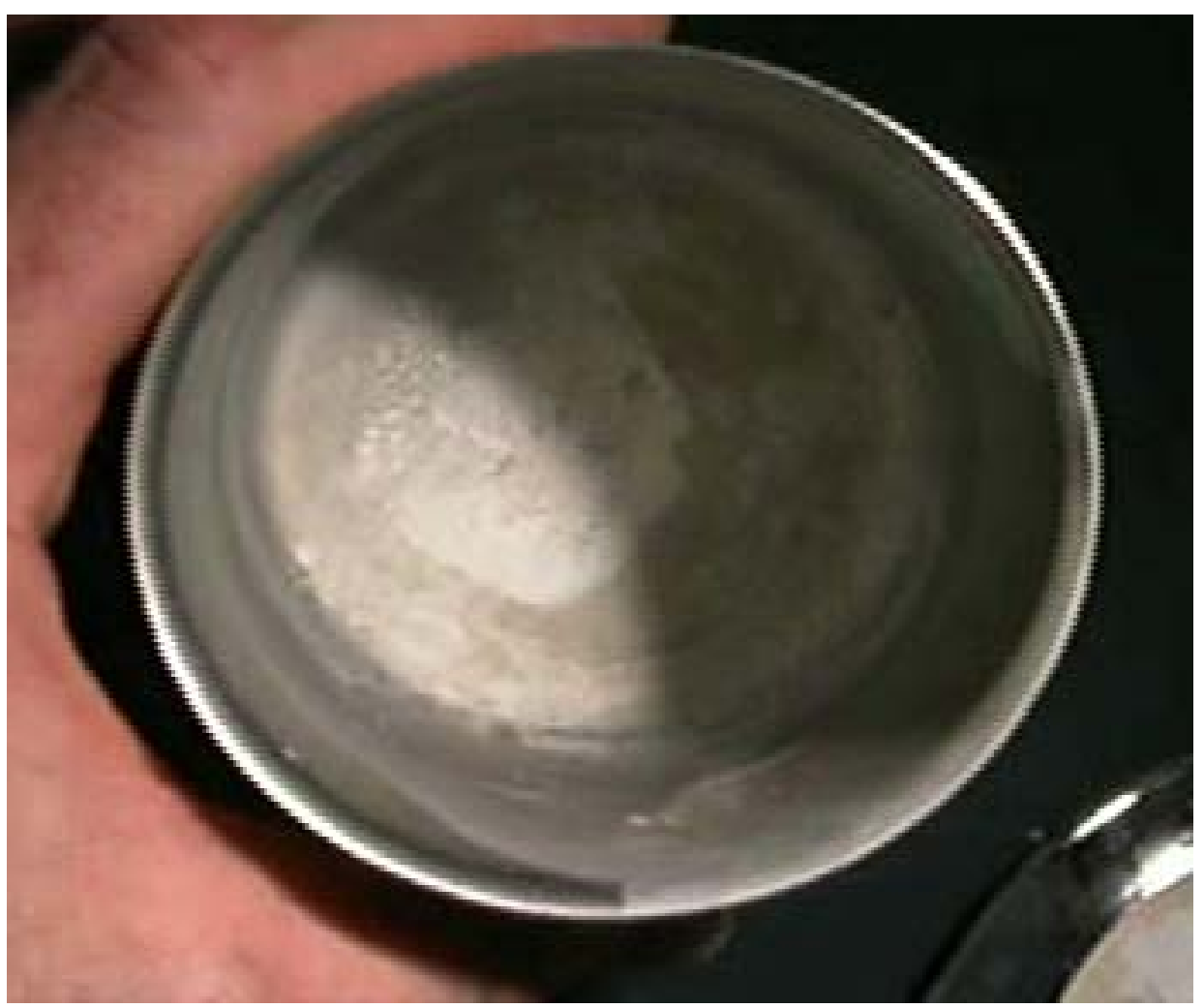

Figure 15. Stainless steel beaker after reaction for the high mixing batch test

\subsubsection{Observed Effect of Mixing}

For the standard $0.1 \mathrm{M} \mathrm{Si} / \mathrm{Al}$ reaction at $80^{\circ} \mathrm{C}$ for 2 hours, shows a clear effect of mixing on deposition. Under this high supersaturation, where both homogenous initiation mechanisms as well as heterogeneous initiation mechanisms are accessible, increased mixing appears to have a significant effect both on the amount of deposit and the geometric distribution of deposited material. As the mixing spectrum is traversed from no mixing through high mixing a region of transition likely could occur where the effects on deposits are difficult to discern.

For the conditions employed in this study the highest mixing conditions clearly reduced the overall deposition coefficient. Although the low mixing deposition coefficient is not dramatically different from the unmixed deposition coefficient, the structure clearly imparted to the deposited aluminosilicate and the general relation to the expected hydrodynamics of the system strongly indicate the importance of hydrodynamics with regard to deposition of solids. The effects of mixing for system compositions such as our evaporator have also been observed in the work of ORNL ${ }^{2,3}$ and Addia-Mensah at the University of South Australia. ${ }^{4}$ 
The much higher precision in the high mixing case also suggests that in the regime of low mixing there is a greater sensitivity to changes in mixing characteristics. It appears that during this transition regime small changes or variations in mixing can lead to large changes in the observed deposition coefficient. ${ }^{4}$ In conditions of high supersaturation, where homogeneous initiation mechanisms exist, it is very likely that the accumulation of aluminosilicate on a stainless steel substrate could be reduced significantly with judicious selection of mixing to impart desired hydrodynamic character to the system.

\subsubsection{Pre-formation Tests}

The aging or "preformed" series of tests was designed to assist in simulating the reaction of any supersaturated silicon and aluminum in the feed tank prior to entry into the evaporator system. It has been previously documented that the aluminosilicates observed under experimental conditions, such as those in our evaporator system, progress through a series of phases as the equilibrium phase is approached. The initial colloidal sols are believed to agglomerate into a loosely formed highly hydrated network that is gelatinous or amorphous in character. This unstructured phase then sequentially dehydrates and densifies through a number of crystalline phases. Zeolite A, sodalite, and cancrinite are members of the likely transition sequence. One area of interest is whether all of these phases have similar deposition affinity for a stainless steel substrate. To assist in evaluating this envisioned possibility the aging tests were designed and performed.

In these deposition experiments the reactive evaporator feed solution was prepared and placed in a polyethylene container at $80^{\circ} \mathrm{C}$ for varying amounts of time. Aluminosilicate solids were formed, but did not adhere to the polymeric container. The resulting slurry was then transferred into the stainless steel beaker and the regular 2-hour deposition test at $80{ }^{\circ} \mathrm{C}$ was performed. The preformed tests were performed in an unmixed configuration. The times of pre-formation were 2,4 , and 8 hours.

The solids present in the filtrate as well as the solids adhered to the stainless steel vessel were dried and weighed. The results are shown in Table 1 . The mean of the three triplicate measurements for pre-formation times of 2,4 , and 8 hours were $22 \%, 19 \%$, and $9 \%$, respectively. The $80 \%$ confidence interval of the 2,4 , and 8 -hour preformed tests were $+/-3 \%,+/-6 \%$, and $+/-2 \%$ respectively.

The baseline unmixed deposition coefficient was $65 \%$. The resulting deposition was dramatically decreased under these preformed conditions. It appears that the largest reduction in subsequent deposition occurs in the early stages of pre-formation. Namely, for the conditions evaluated, less than two hours of pre-formation at $80{ }^{\circ} \mathrm{C}$ leads to a precipitous decrease in deposition (from $65 \%$ to $22 \%$ at 2 hours of pre-formation). It also appears that a continual decrease in deposition affinity is observed for preformed material with more preformation time. This could be the result of a large number of effects. 
The supersaturation is decreasing during the pre-formation time that could readily affect the partition between homogenous and heterogeneous avenues of formation in the stainless steel vessel once the material is transferred. The previously hypothesized difference in deposition affinity for various phases could be operative. Most likely, both of these phenomena contribute to the observed effects. Figure 16 is an image of the stainless steel beaker after undergoing a two-hour preformed test. As indicated by the deposition coefficients this image reinforces the dramatic decrease in deposition. Images of preformed tests for the 4 and 8 -hour time frames demonstrate very similar characteristics.

Table 1. Summary of Results for Batch Testing

\begin{tabular}{|c|c|c|}
\hline Experiment Type & Mean for Deposition & Confidence Interval 80 \\
\hline No Mixing & $65 \%$ & $\pm 9 \%$ \\
\hline Low Mixing $(<0.2 \mathrm{~W} / \mathrm{Kg})$ & $49 \%$ & $\pm 17 \%$ \\
\hline High Mixing (0.4-0.8W/Kg) & $15 \%$ & $\pm 3 \%$ \\
\hline Preform (2 hours) & $22 \%$ & $\pm 3 \%$ \\
\hline Preform (4 hours) & $19 \%$ & $\pm 6 \%$ \\
\hline Preform (8 hours) & $9 \%$ & $\pm 2 \%$ \\
\hline $\begin{array}{l}\text { High Mixing }(0.4-0.8 \mathrm{~W} / \mathrm{Kg}) \\
\text { and Preform ( } 8 \text { hours })\end{array}$ & $4 \%$ & $\pm 2 \%$ \\
\hline
\end{tabular}

\subsubsection{High Mixing and Pre-formation in Tandem}

Based on the previous observation of the dramatic effects of mixing and pre-formation had on deposition affinity, a series of tests were designed and performed that evaluated the deposition coefficient in a system that had experienced both effects. Namely, the 8-hour preformation period was utilized, followed by a 2-hour period at $80{ }^{\circ} \mathrm{C}$ in the stainless steel beaker being stirred under the high mixing condition.

The solids present in the filtrate as well as the solids adhered to the stainless steel vessel were dried and weighed. The mean of the three triplicate measurements for this dual effect test was $4 \%$ with an $80 \%$ confidence interval of $+/-2 \%$. The baseline deposition coefficient was $65 \%$. The resulting deposition observed under these dual conditions was dramatically decreased. 


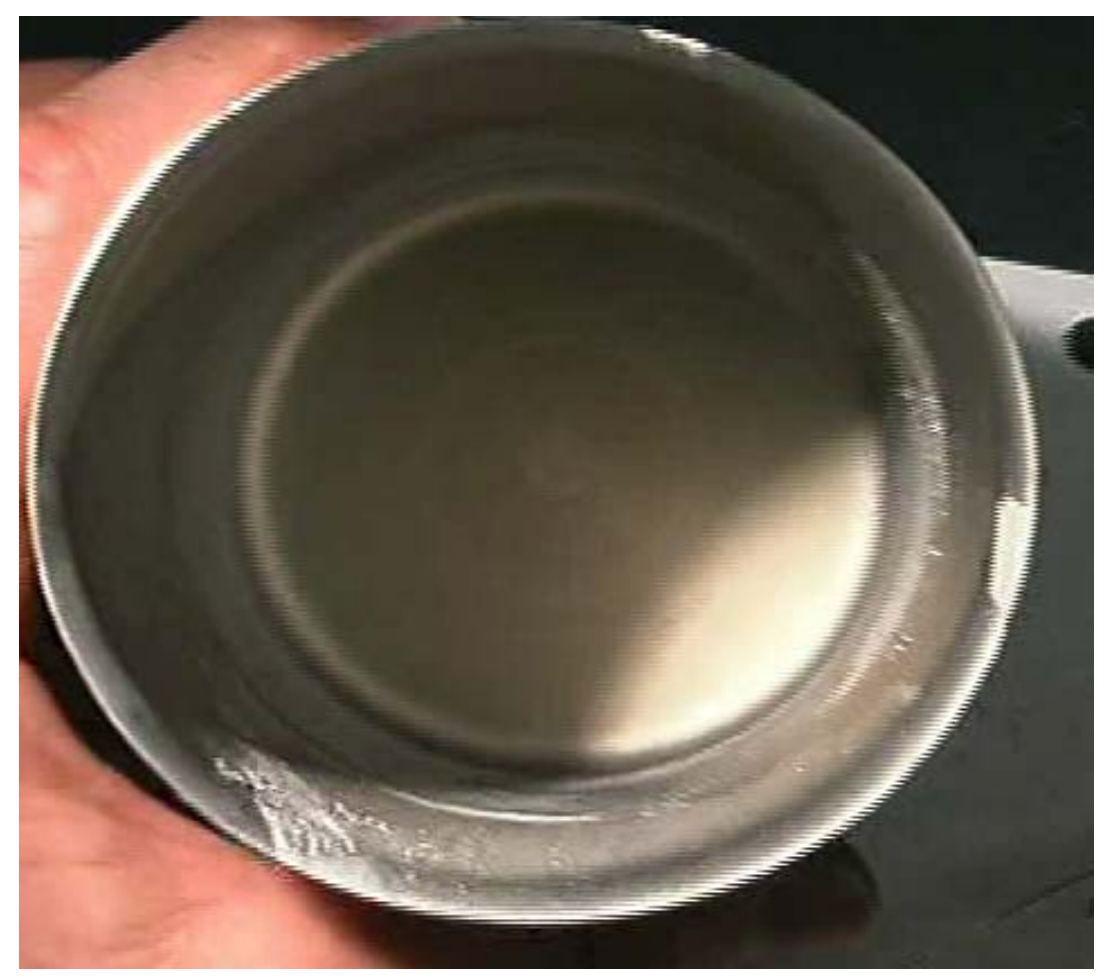

Figure 16. Stainless steel beaker after reaction for a two-hour preformed test

\subsubsection{Summary of Batch Testing Results}

The mean deposition coefficients and precision confidence intervals for all batch testing are summarized in Table 1. For the conditions evaluated, increased mixing reduces the deposition coefficient dramatically. Likewise, increased aging or pre-formation time dramatically decreases the deposition. These two effects, when introduced in tandem, act together to demonstrate a large decrease in deposition. The resulting combination of effects decreases the mass of material deposited by more than an order of magnitude.

\subsection{CONTINUOUS FEED RESULTS}

Aluminosilicate deposition testing was performed according to the methodology discussed in Section 2.5. The conditions evaluated were no mixing, low mixing, and high mixing, as well as a series of tests using seeds to evaluate the effects on deposition to the reaction vessel.

The tests were conducted for six hours. The reaction vessel was continually fed a supersaturated solution of aluminum and silicon as described in Section 2.3. The feed rate was selected to yield three reactor volume turnovers during the course of the 6-hour experiment. This two-hour residence time corresponded to approximately $100 \mathrm{ml}$ per hour. 
At the end of each six-hour test, the discharged solution was filtered to characterize the mass of solids that was carried out of the vessel. The solution from the beaker at the end of the experiment was also collected and filtered. The beaker was rinsed several times with de-ionized water to assist in removal of loosely adhered solids and these were added to the beaker solution. Both the filtered solids and the deposited solids on the internal surfaces of the vessel were dried and weighed. Filtration occurred through a Whatman \#42 filter and the samples were dried at $105^{\circ} \mathrm{C}$ until constant weight (4hours). Selected samples were sent for characterization, including but not limited to $\mathrm{x}$-ray diffraction and scanning electron microscopy. A deposition coefficient was determined by looking at the percentage of the total solids formed that adhered to the stainless steel beaker.

The stainless steel reaction chamber was cleaned using $2 \mathrm{~N}$ sulfuric acid between runs. The cleaned beaker was rinsed with copious de-ionized water and then dried at $105{ }^{\circ} \mathrm{C}$ for 4 hours. The beaker was considered clean when the sample weight was within .05 grams of the baseline beaker weight obtained before the first experiment. This corresponds to $<0.02 \%$ change.

\subsubsection{Unmixed Deposition Testing}

For the unmixed testing sequence, the initial reactor volume, consisting of 4M-sodium hydroxide containing $1 \mathrm{M}$ each of sodium nitrate and sodium nitrite, was heated to $80{ }^{\circ} \mathrm{C}$. The supersaturated $\mathrm{Al} / \mathrm{Si}$ solution was fed to the vessel at approximately $1.7 \mathrm{ml} / \mathrm{minute}$. The stirring shaft was in place in the vessel to maintain the same interior surface area as the mixing tests.

The solids present in the discharged solution and the solution in the vessel were dried and weighed. The vessel was also dried and weighed to obtain the solids that did adhere. The ratio of the amount of solids that deposited to the amount of solids that were formed was calculated. The mean percent deposition of this series was $81 \%$ with an $80 \%$ confidence interval of $+/-10 \%$. As with the batch testing, most of the solids that were formed adhered to the bottom of the reaction chamber, most likely due to settling of the solids. A photo of the reaction chamber after the experiment is shown in Figure 17.

Samples of the suspended and deposited solids were analyzed by x-ray diffraction and scanning electron microscopy. An x-ray diffraction from the solids scraped from the deposition chamber is shown in Figure 18 and an $\mathrm{x}$-ray diffraction spectrum for the solids not adhered to the stainless steel but rather suspend in the bulk of the liquor is shown in Figure 19.

The x-ray diffraction showed essentially the same spectrum, not only for the solids adhered to the wall and the bulk solution, but for the continuous and batch experiments as well. Figure 20 shows the scanning electron microscopy of the solids adhered to the beaker, while a scanning electron microscopy of the solids from the bulk solution is shown as Figure 21.

The same yarn-ball structures are seen for the continuous test as were seen in the batch testing. The solids apparently have very similar microstructure regardless of their location in the experimental system. 


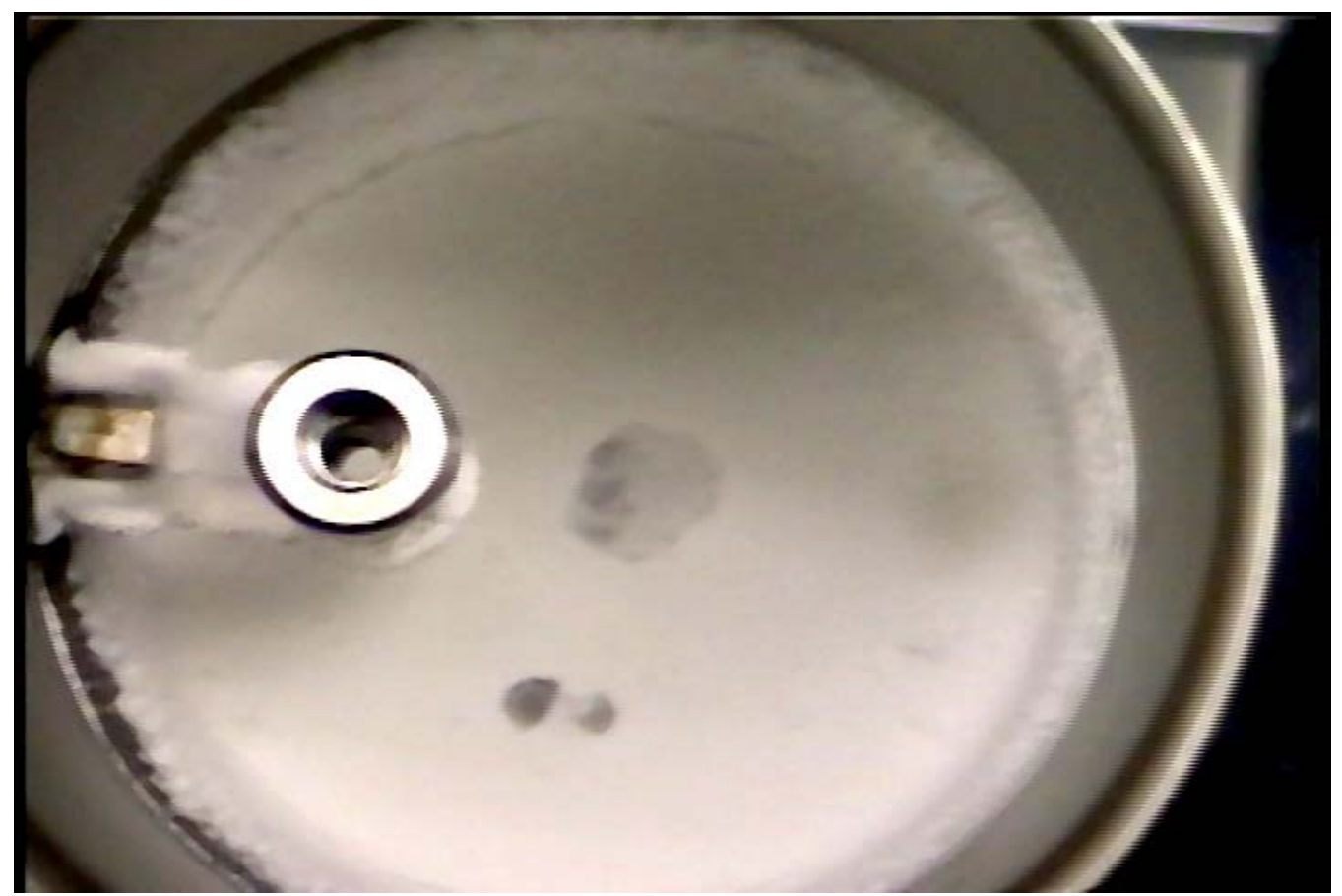

Figure 17. Stainless steel beaker after reaction for unmixed continuous test

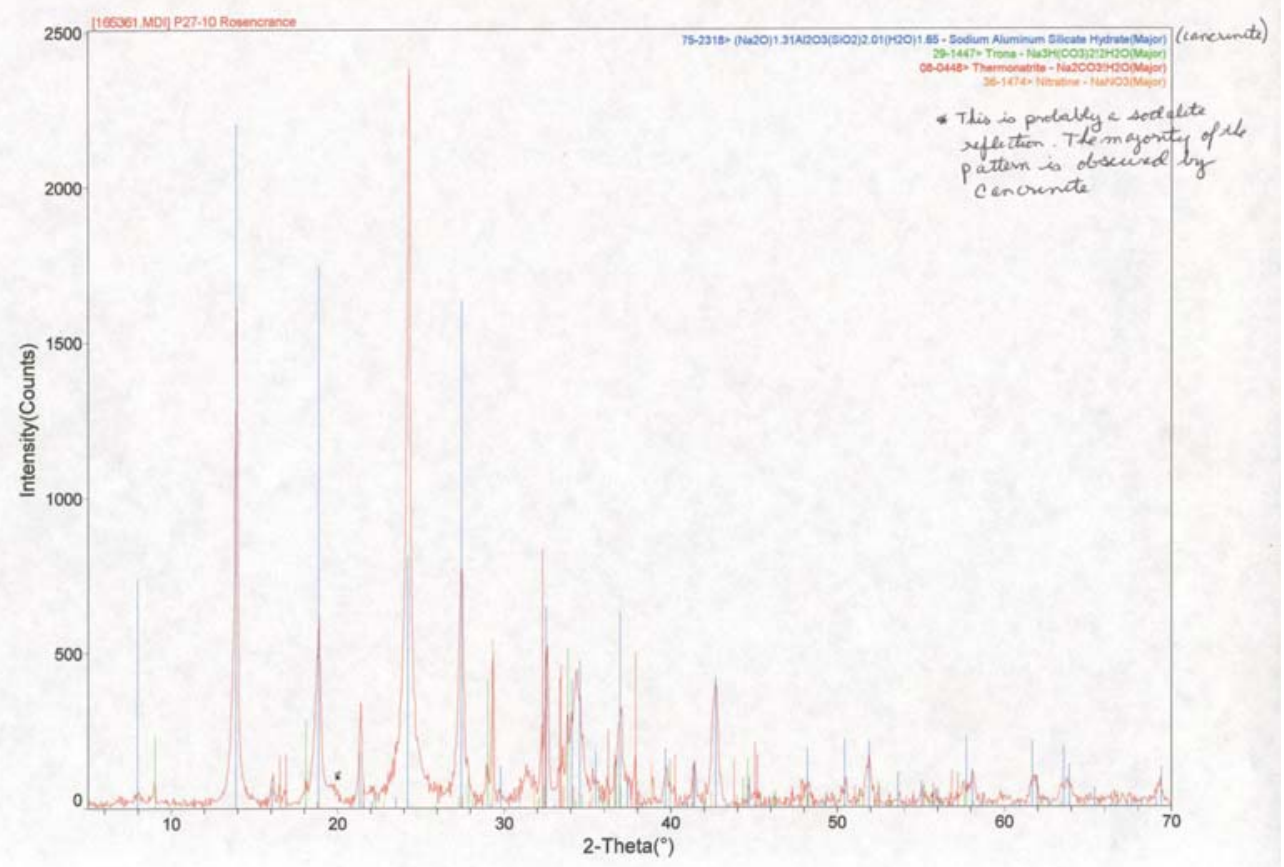

Figure 18. X-ray diffraction spectrum of solids from beaker wall of unmixed continuous test 
WSRC-TR-2001-00464, REVISION 0

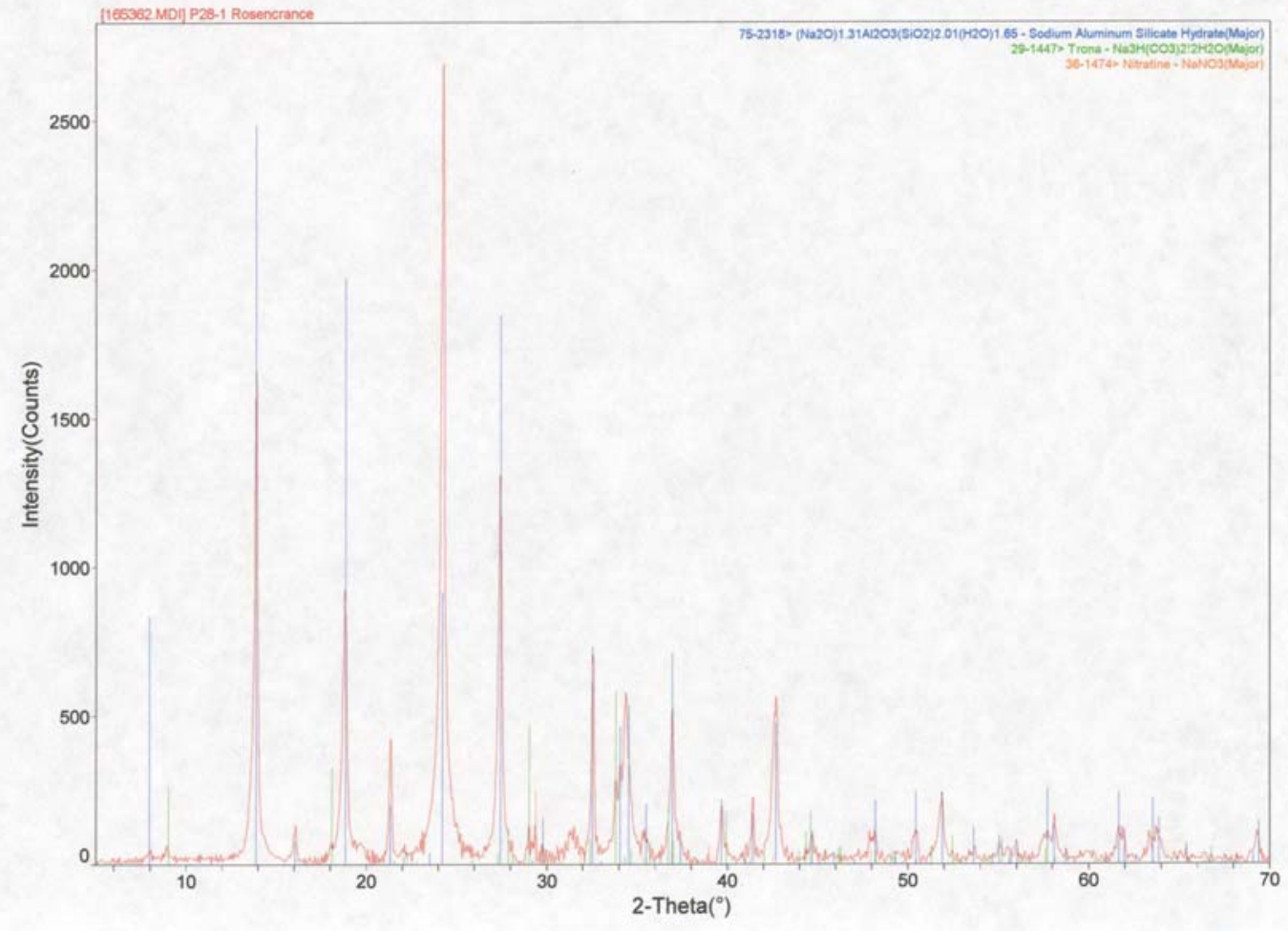

Figure 19. X-ray diffraction spectrum for non-deposited solids from continuous unmixed test 

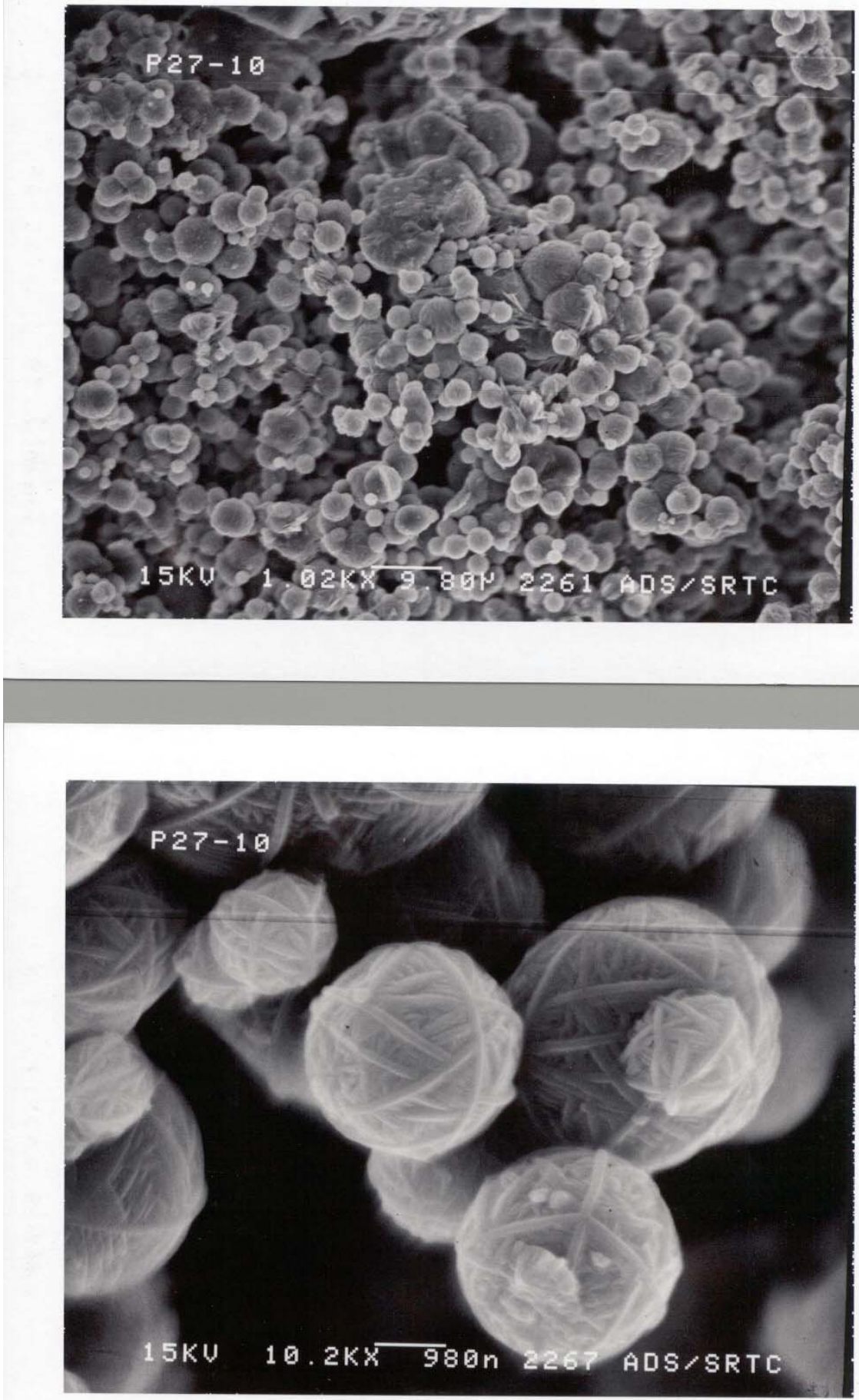

Figure 20. Scanning electron microscopy of deposited solids from unmixed continuous test

Note: Bottom view is magnified 10X relative to top photo.

Page 27 of 44 

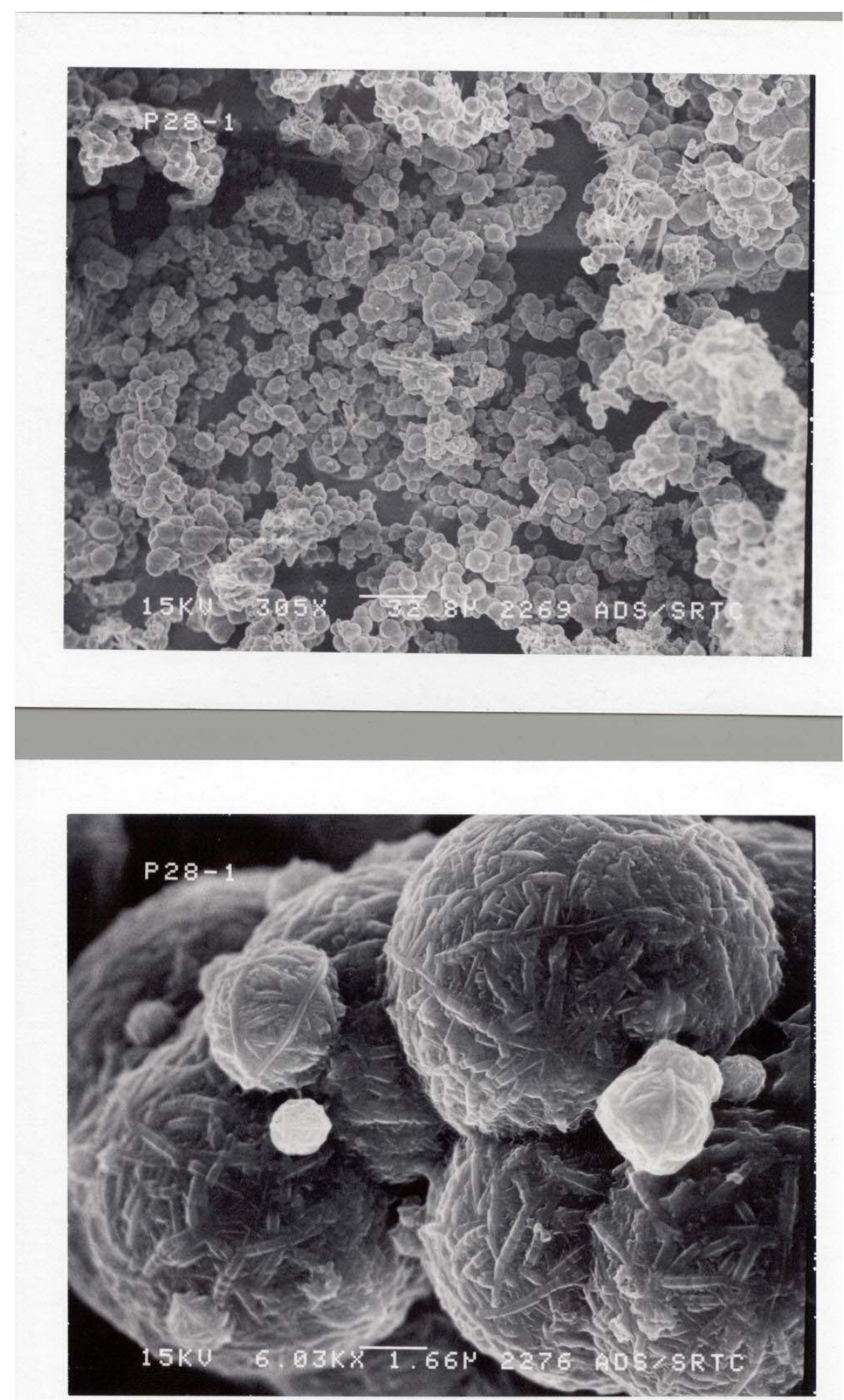

Figure 21. Scanning electron microscopy of non-deposited solids from unmixed continuous test.

Note: Bottom view is magnified 20X relative to top photo. 


\subsubsection{Low Mixing Continuous Testing}

The same test configuration was used in the continuous unmixed tests, except that the agitator was operated at $90 \mathrm{rpm}$. The initial bulk fluid was the nitrate-nitrite modified hydroxide solution to which the supersaturated $\mathrm{Al} / \mathrm{Si}$ solution was fed. The resulting solutions were filtered and weighed. The mean solids deposited were $77 \%$ with an $80 \%$ confidence interval of $+/-1 \%$. A representative photo of the beakers from this series of experiments is shown in Figure 22.

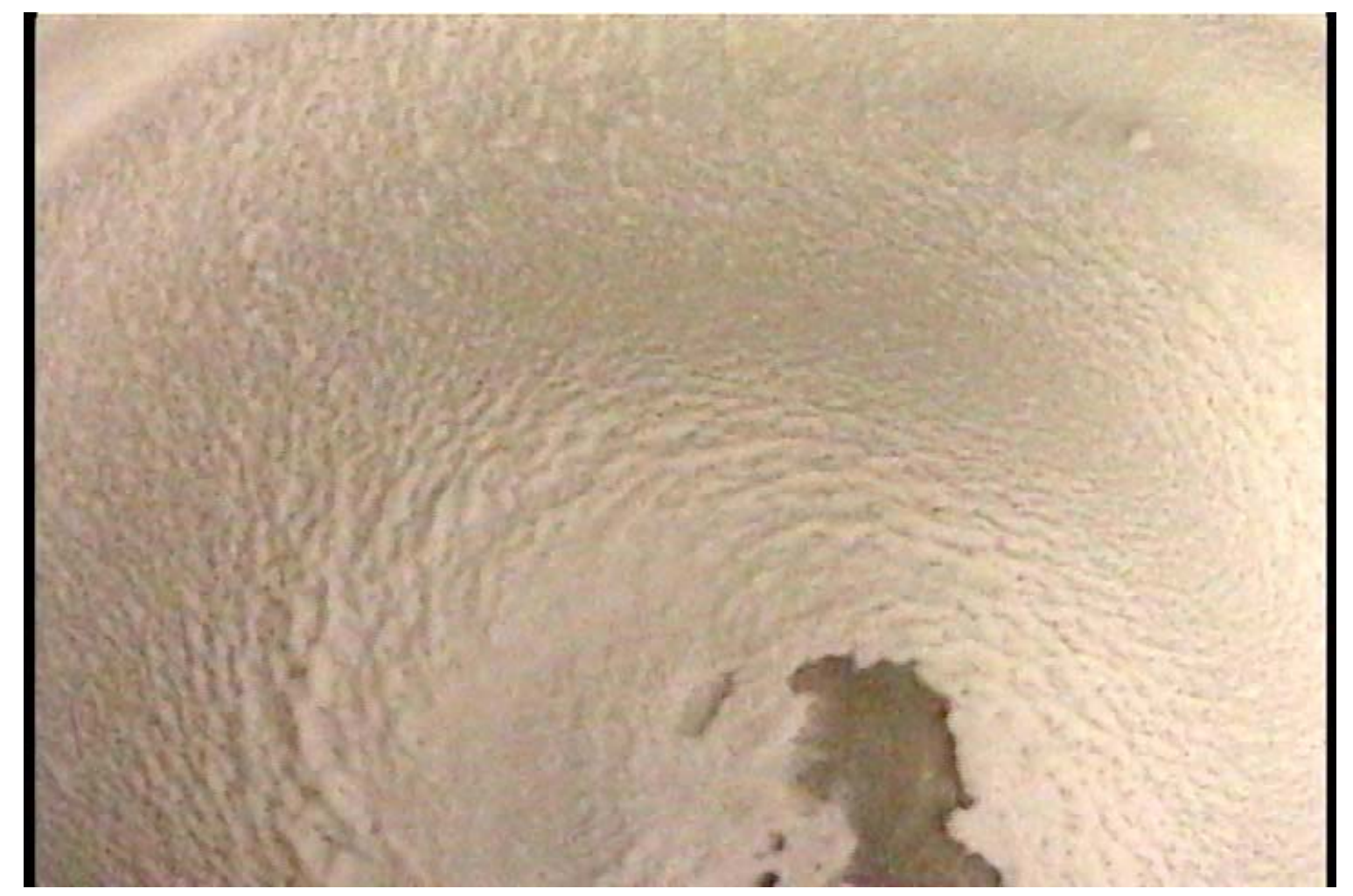

Figure 22. Stainless steel beaker after reaction for the low mixing continuous test

\subsubsection{High Mixing Continuous Testing}

For the high mixing series of tests the agitator speed was increased to $250 \mathrm{rpm}$. The increased mixing resulted in a deposition of $37 \%$ with an $80 \%$ confidence interval of $+/-11 \%$. A representative photo of the reaction vessel from this series of testing is shown in Figure 23. 


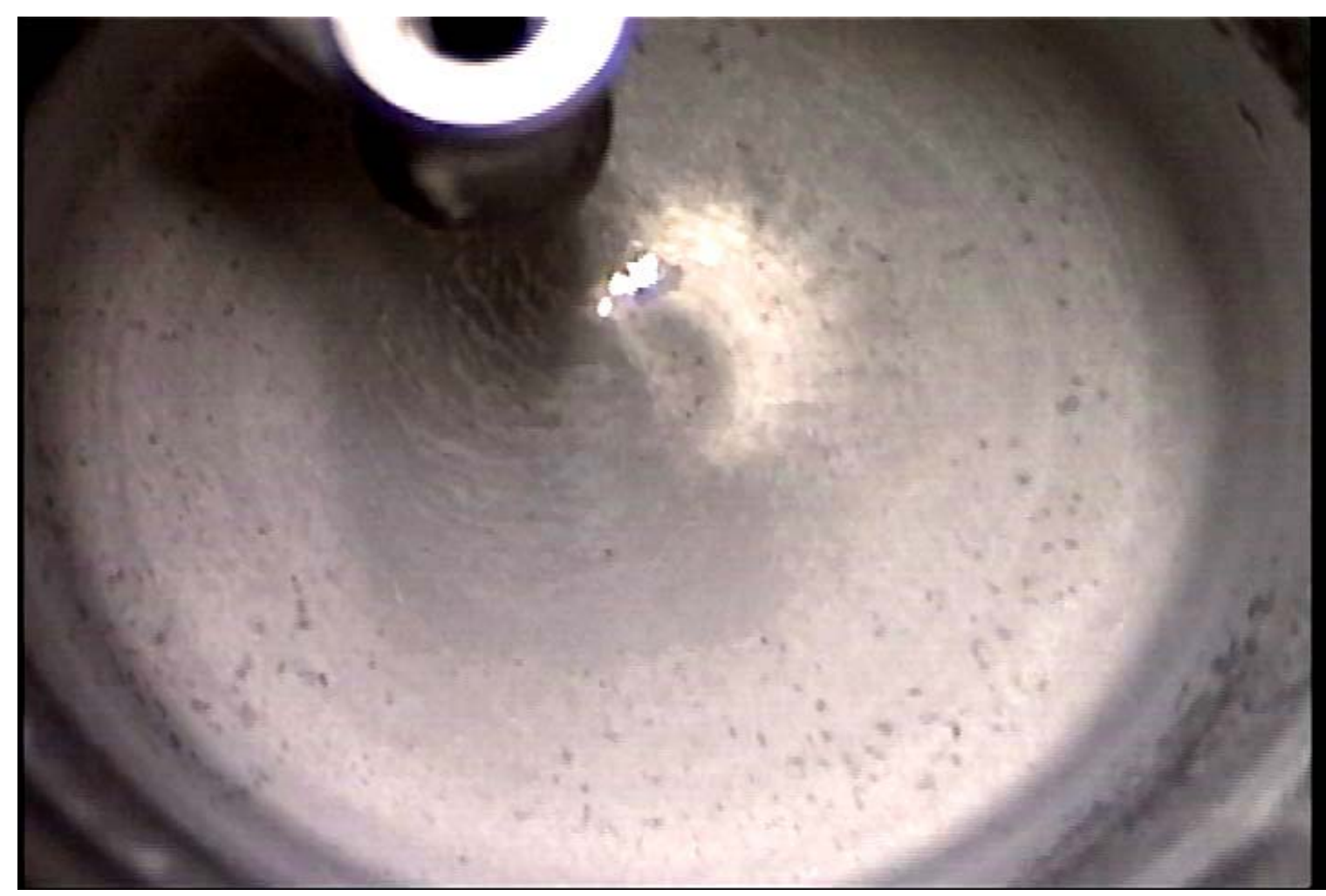

Figure 23. Stainless steel beaker after reaction for the high mixing continuous test

During the high mixing tests problems were encountered with the 1/4-inch overflow discharge tube plugging. The tubing had to be cleared manually on occasion due to solids deposition. This clearing was performed without stopping the experiment by simply inserting a narrow metal rod back into the overflow tube while the experiment continued. The primary cause is believed to be the sudden loss of velocity in the overflow and discharge tubes. This decrease in suspended particle velocity allowed the solids to adhere to the stainless steel surfaces.

\subsubsection{Seeding/High Mixing Continuous Testing}

The seeding tests used the same configuration as the high mixing testing. The high mixing test was used to ensure that the seeds remained in suspension to maximize their effectiveness. As described in Section 2.3, 0.25 grams of seeds were added every 30 minutes starting with time zero of the experiment. The last addition was made 5 hours and 30 minutes into the experiment. The seeds were slurried in $2 \mathrm{ml}$ of hydroxide and added to the bulk solution.

The total solids deposited on the stainless steel beaker were $0.64+/-0.21$ grams. The total solids deposited on the beaker during the high mixing tests was $2.12+/-0.54$ grams. Thus the seeding resulted in the amount of solids deposited on the beaker being reduced by 70 percent. Figure 24 shows a beaker from the seeding tests. 


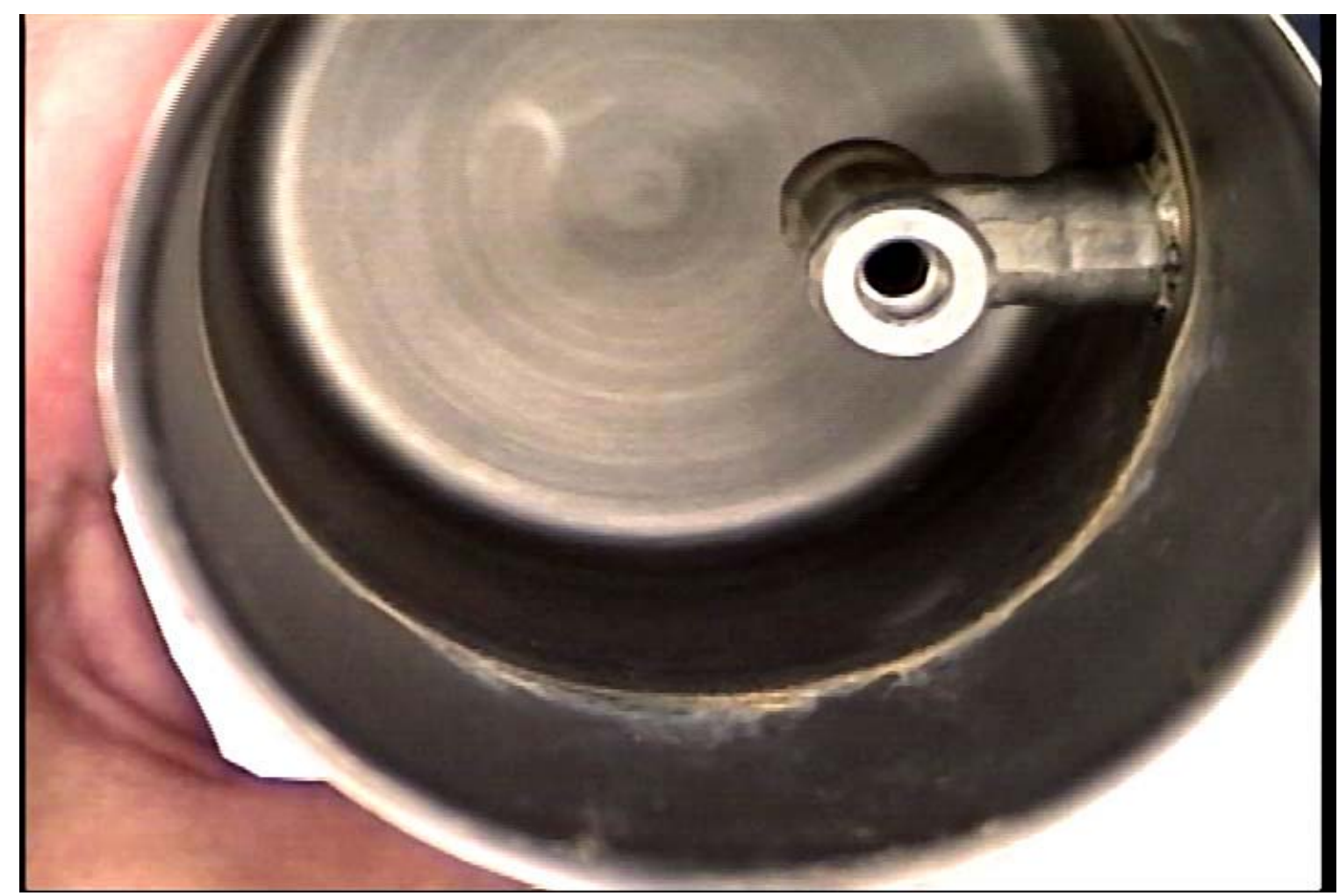

Figure 24. Stainless steel beaker after reaction for the seeded continuous test

As with the high mixing tests, plugging occurred in the overflow line. This was again due to the loss of velocity in the overflow "T" and piping. The suspended material fell out of suspension and caused the line to become plugged. The blockages were easily cleared and did not adhere to the surface. These observations of suspended material in the overflow line should be considered with regard to the previous operational difficulty in the GDL. A large portion of the solids in the seeding test remained in the reaction vessel. At the end of the experiment there was a significant amount of solids in the vessel that were not adhered to the stainless steel. The settled seed particles were easily removed from the bench-top vessel by rinsing.

Samples of the unreacted seed particles (as well as the suspended and deposited solids formed during the seeding experiment) were analyzed by x-ray diffraction and scanning electron microscopy. The $\mathrm{x}$-ray diffraction for the unreacted chabazite seed material is shown in Figure 25. An x-ray diffraction from the solids scraped from the deposition chamber is shown in Figure 26. An x-ray diffraction spectrum for the solids not adhered to the stainless steel but rather suspend in the bulk of the liquor is shown in Figure 27. 
WSRC-TR-2001-00464, REVISION 0

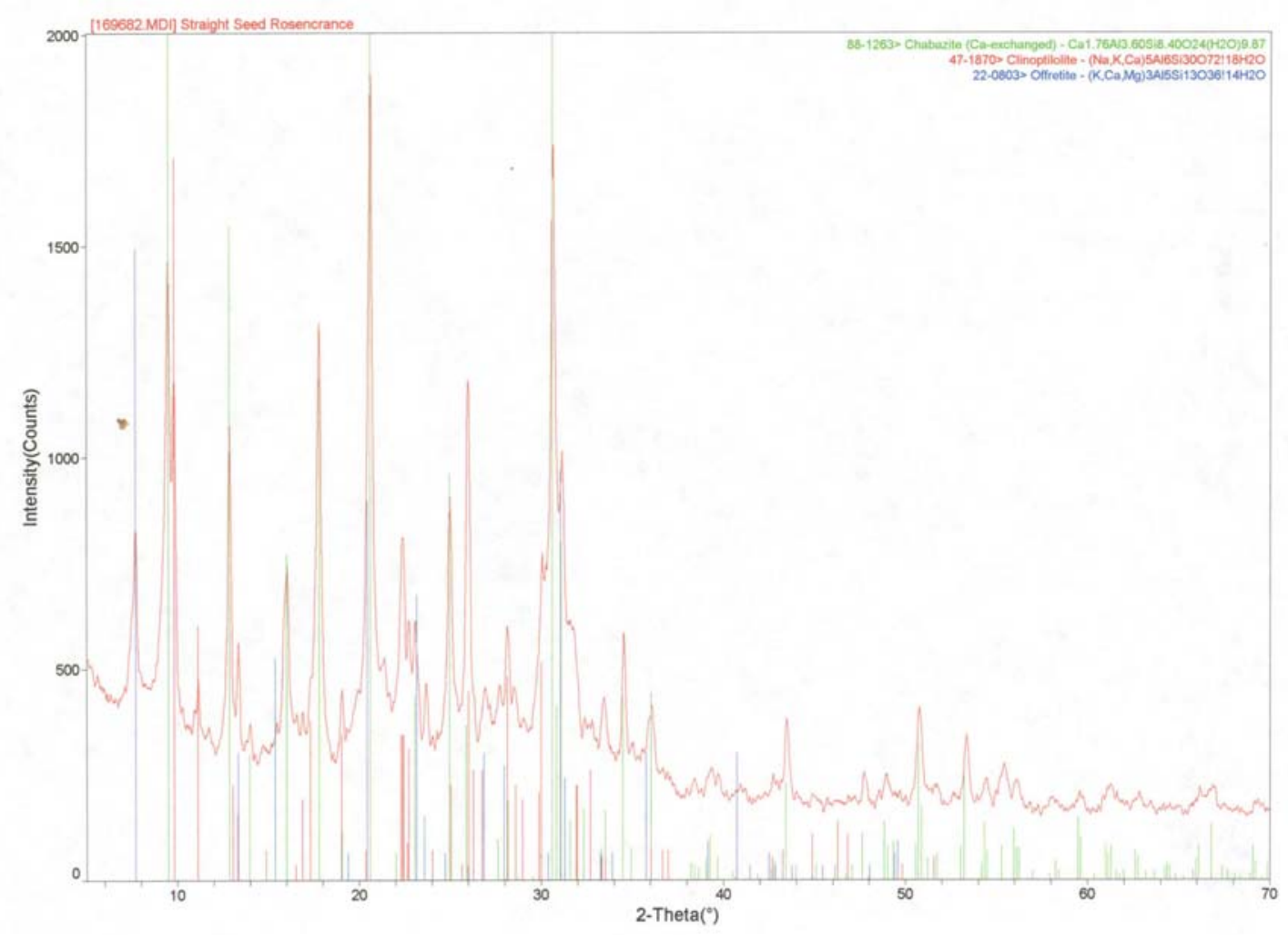

Figure 25. X-ray diffraction of unreacted seed particles 


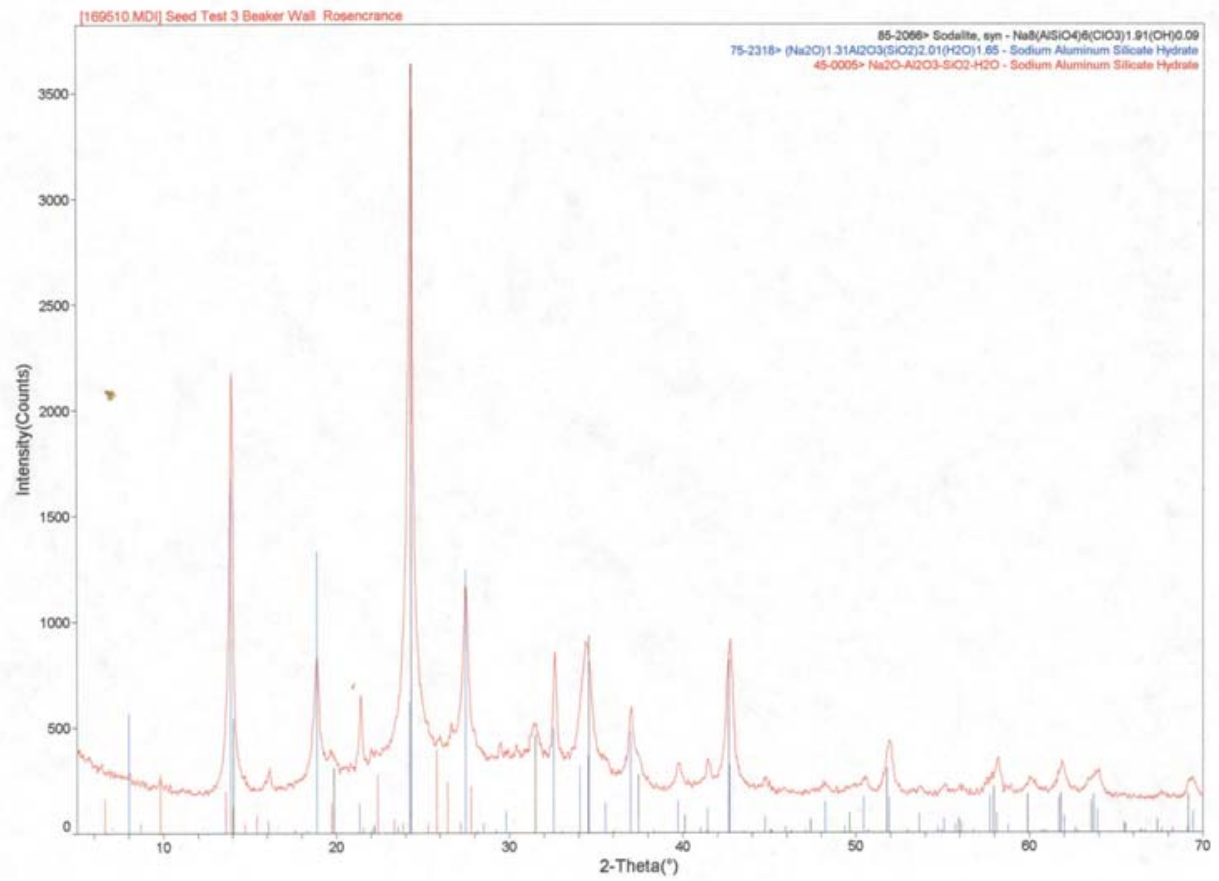

Figure 26. X-ray diffraction spectrum of deposited solids for seeded continuous test

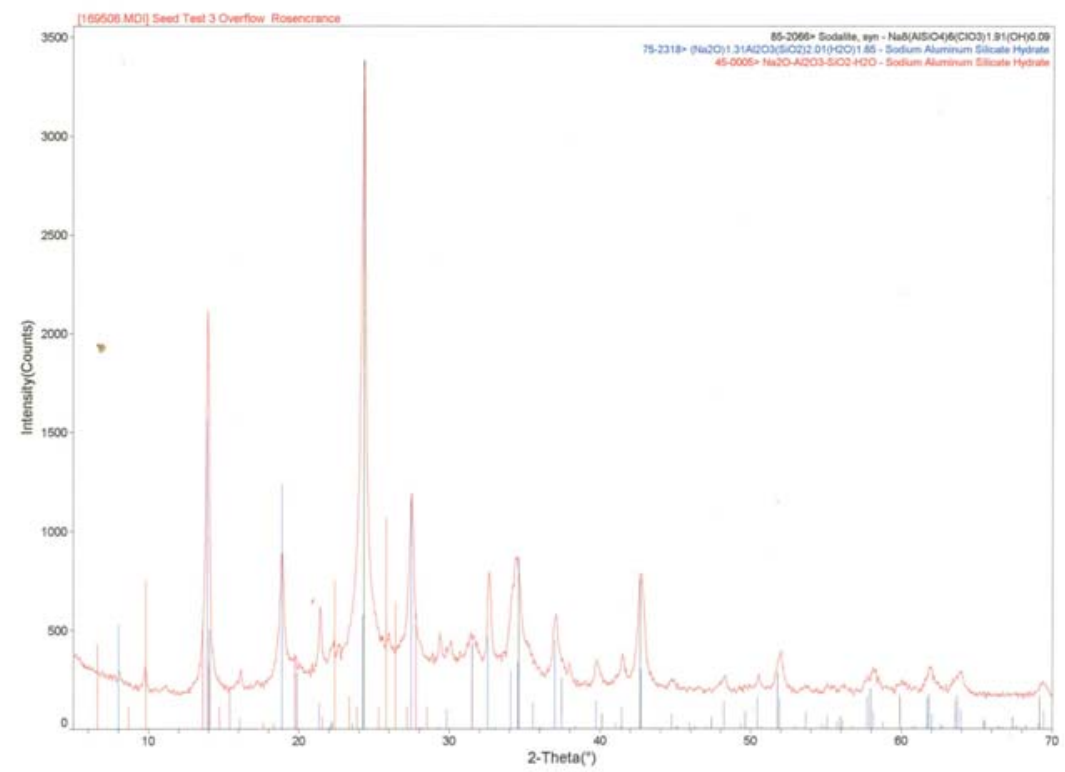

Figure 27. X-ray diffraction spectrum of non-deposited solids from seeded continuous test 
The x-ray diffraction spectra of the unreacted seed verified the seed material phase as predominately chabazite. The x-ray diffraction following reaction (for the solids adhered to the wall and the bulk solution) were essentially the same as each other and indicate sodalite. Chabazite is not observed in the $\mathrm{x}$-ray diffraction spectra following reaction. These spectra of the material following reaction were also essentially the same as those observed for the solids formed in the previous batch testing. This strongly suggests, in tandem with morphological information from scanning electron microscopy that is to follow, that the chabazite particles are indeed seeding the reaction and preferentially consuming the reactive supersaturation to form sodalite based coatings on the chabazite seed material.

Figure 28shows the scanning electron microscopy for the unreacted seed particles. Figure 29 and Figure 30 are scanning electron microscopy results for the deposited and non-deposited solids produced in the seeded continuous tests. Figure 31 is a scanning electron microscopy showing a coarse seed particle which as not been coated during the reaction period.

As shown in Figure 28, the chabazite seed material has two significantly different characteristics. The morphology of the seed particles is neither spherical nor cubic as traditionally observed for the zeolite A and sodalite solid phases produced during reaction. Secondly, the dispersity of the particle size distribution appears to be much greater. Although several very large particles are observed a correspondingly large number density of very fine material is present in the unreacted seed. This large number of fines provides the vast majority of the surface area that is presumably extremely important in order to accentuate the heterogeneous nucleation process on surfaces other than the stainless steel.

Figure 29 and Figure 30 are scanning electron microscopy photos, following reaction, of the deposited and non-deposited solids respectively. Clearly, the morphology of the solids produced during the seeding experiment is quite different than previously observed for all continuous and batch deposition tests reported. The spherical structure that is the dominant feature in previous tests is replaced with a highly fused structure containing hints of sphericity. This change in the structures is anticipated and is directly related to the inherently different starting morphology of the seed material.

As previously mentioned, the initial morphology of the seed material is noticeably different and characteristic of grinding and/or milling processes which were used to prepare the seed. Figure 31 shows a scanning electron microscopy view of a single coarse particle that is presumably an unreacted chabazite seed. Although the statistical probability of this occurring is unknown, this observation validates the need to evaluate the seeding process to ensure proper implementation. Selection of seed characteristics, both chemical and physical, will be important in developing a mitigation strategy founded on seeding. 

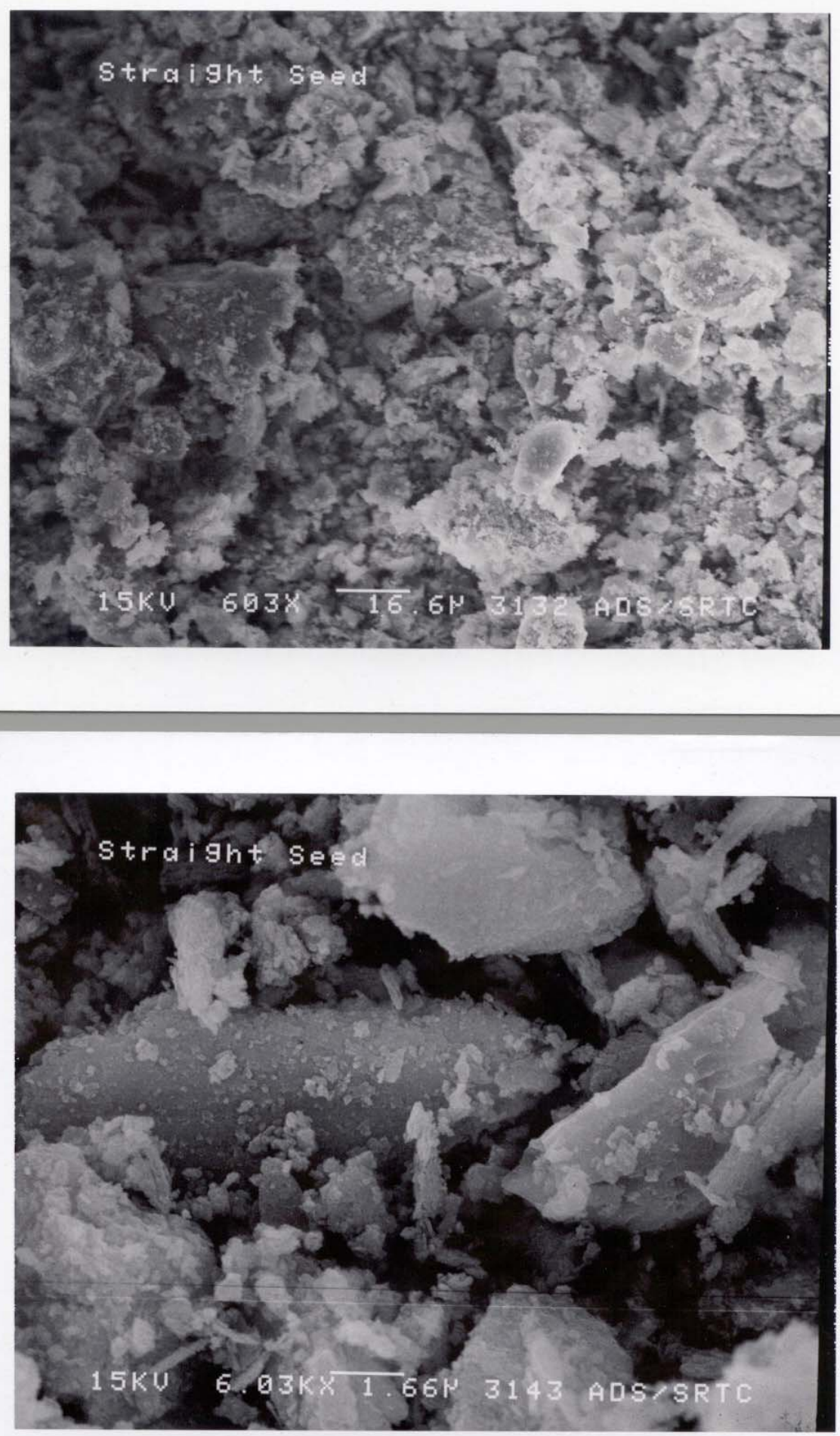

Figure 28. Scanning electron microscopy of unreacted seed particles

Page 35 of 44 

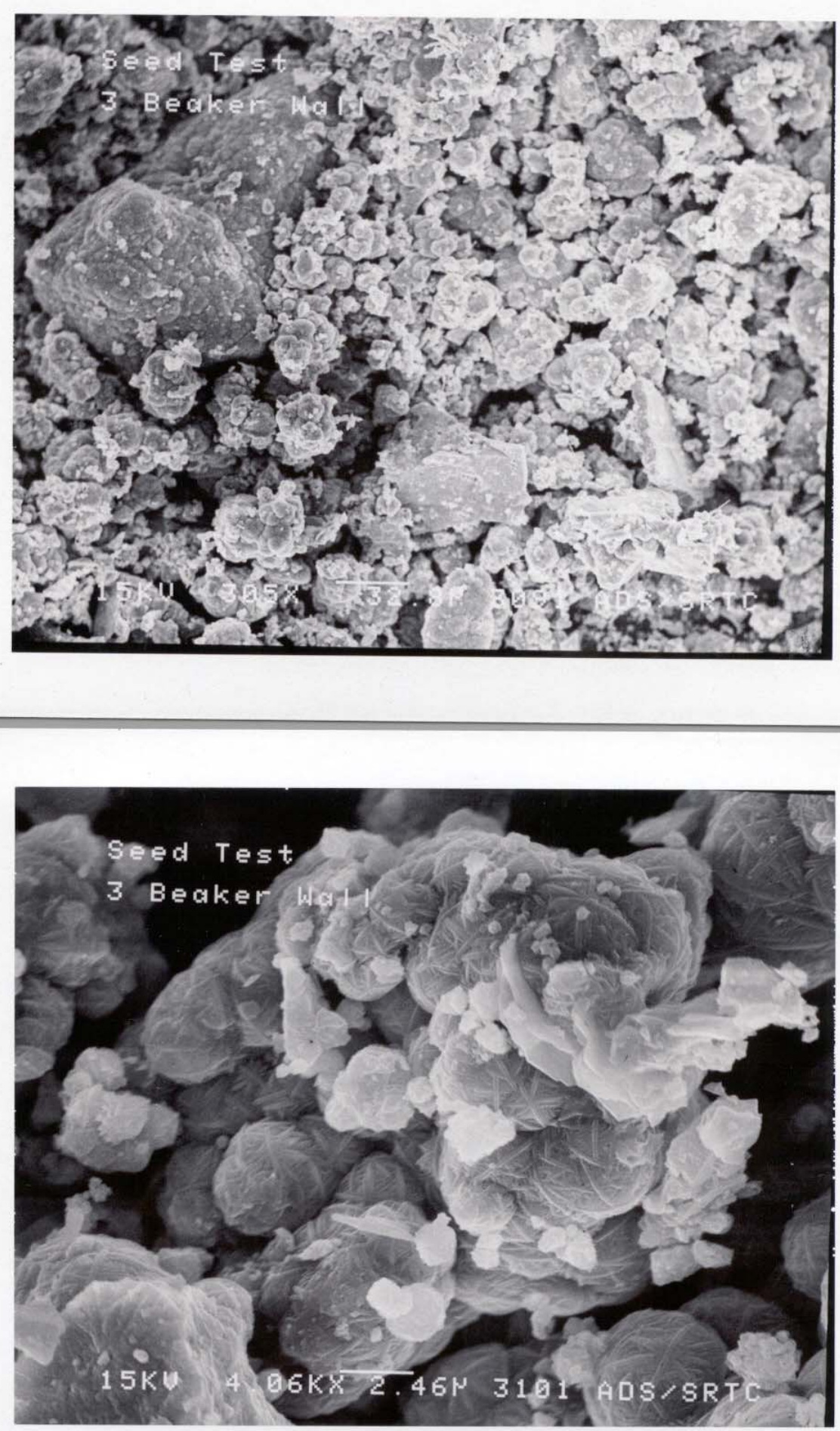

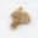

Figure 29. Scanning electron microscopy of deposited solids from seeded continuous test 

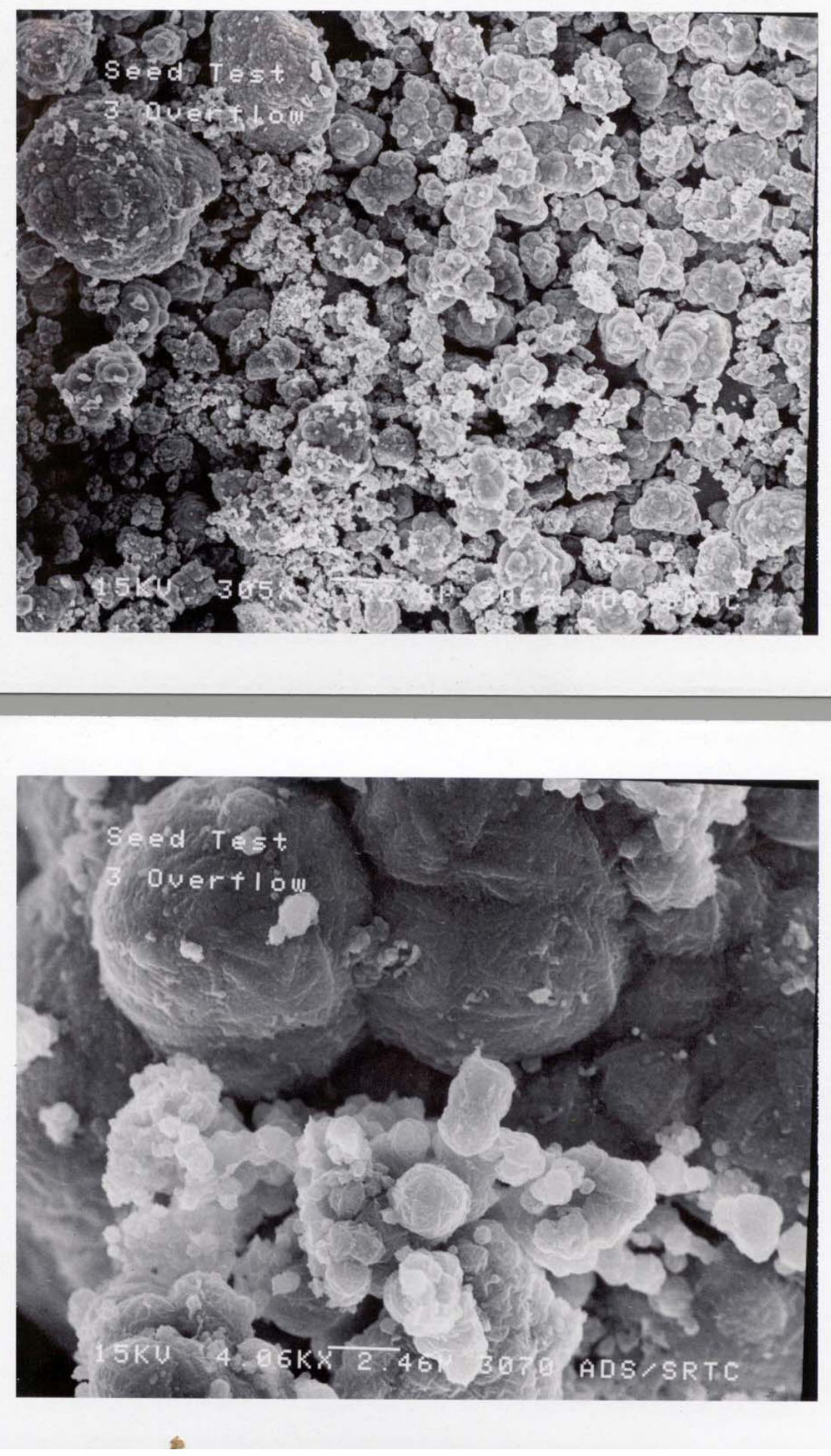

Figure 30. Scanning electron microscopy of non-deposited solids from seeded continuous test 


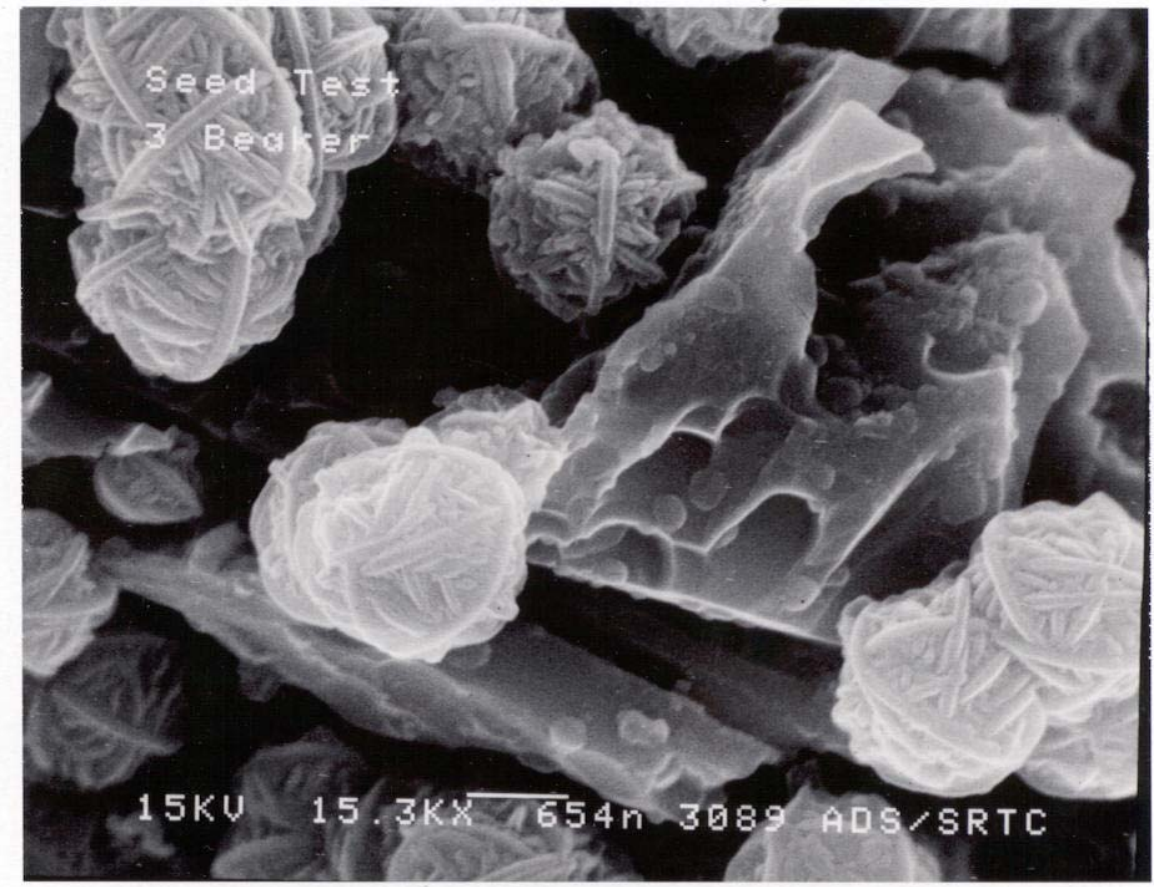

Figure 31. Scanning electron microscopy of an unreacted coarse seed following reaction in seeded continuous test

\subsubsection{Summary of continuous Testing Results}

The mean deposition coefficients and confidence intervals for continuous feed testing of mixing effects are summarized in Table 2. For the conditions evaluated, increased mixing reduces the deposition coefficient dramatically. Test results were consistent with those of the batch tests.

Table 2. Summary of Mixing Effects in Continuous Feed Testing

\begin{tabular}{|l|c|c|}
\hline Experiment Type & Mean for Deposition & Confidence Interval 80 \\
\hline No Mixing & $81 \%$ & $\pm 10 \%$ \\
\hline Low Mixing $(<0.2 \mathrm{~W} / \mathrm{Kg})$ & $77 \%$ & $\pm 1 \%$ \\
\hline High Mixing $(0.4-0.8 \mathrm{~W} / \mathrm{Kg})$ & $37 \%$ & $\pm 11 \%$ \\
\hline
\end{tabular}


The mean mass of material deposited and the associated confidence intervals for the seeded continuous feed tests are shown in Table 3. The seeding tests demonstrated the least amount of deposition. The seeding tests were run under the high mixing conditions in order to ensure efficient use of the added seed material. Additionally, the seeded material showed less deposition even in dead areas of flow.

Table 3. Summary of seeding Effects in Continuous Feed Testing

\begin{tabular}{|l|c|c|}
\hline Experiment Type & Mean Mass Deposited (g) & Confidence Interval 80 (g) \\
\hline Control for Seeded Test & 2.12 & \pm 0.54 \\
\hline Seeded Test & 0.64 & \pm 0.21 \\
\hline $\begin{array}{l}\text { Reduction in Deposits with } \\
\text { Seeds }\end{array}$ & $\longrightarrow 70 \%$ & \\
\hline
\end{tabular}

The discharge plugged in the seeding tests as it did in the high mixing tests. However, this plugging was different and unlike the result of plugging in the high mixing tests. In the unseeded, high mixing tests, the material strongly adhered to the beaker surfaces and had to be mechanically cleaned out. In the seeded tests the accumulated material was loose and could be easily washed away.

Furthermore, the majority of the solids from the seeding tests remained in the beaker in the form of settled material that did not readily adhere. The testing apparatus used for these experiments did not have an adequate removal system for the seeds. While the material did not stick to the vessel, it did form a layer of material in the bottom of the vessel. Based on these observations, a careful evaluation of addition and removal methods for seeds would be necessary to ensure that the added seed material did not exacerbate the accumulation of solids in the vessel. 
This page intentionally left blank.

Page 40 of 44 


\subsection{CONCLUSION}

This laboratory study was designed to begin to provide insight into the deposition process on the $2 \mathrm{H}$ evaporator. These laboratory studies were performed using small volumes of reagents and stainless steel beakers as deposition chambers to represent the evaporator surface. The initial testing was batch testing. The second round of testing was of a continuous feed nature introducing the concept of fresh feed throughout the reaction.

The batch tests results strongly suggested that increased mixing, for the conditions evaluated reduces the deposition coefficient dramatically. Likewise, increased aging or pre-formation time dramatically decreases the deposition in our testing. These two effects, when introduced in tandem, act together to demonstrate a large decrease in deposition. The resulting combination of effects decreases the mass of material deposited by more than an order of magnitude in our laboratory apparatus.

The results from the continuous feed tests also strongly suggest that increased mixing dramatically reduces the deposition coefficient. The seeding tests demonstrated the least amount of deposition. In the seeded tests the accumulated material was loose and could be easily washed away. However, the majority of the solids from the seeding tests remained in the beaker. While the material did not stick to the vessel, it did form a layer of material in the bottom of the vessel. Based on these observations, a careful evaluation of addition and removal methods as well as mixing for seeded systems would be necessary to ensure that the added seed material did not exacerbate the accumulation of solids in the vessel - or cause other problematic issues such as abrasion of the stainless steel vessel. 
This page intentionally left blank.

Page 42 of 44 


\subsection{REFERENCES}

\footnotetext{
${ }^{1}$ W. R. Wilmarth, C. J. Coleman, J. C. Hart, and W. T. Boyce, "Characterization of Samples from the 242-16H Evaporator Wall," WSRC-TR-2000-00089, Savannah River Technology Center, Aiken, S. C., March 20, 2000.
}

${ }^{2}$ A. J. Mattus, C. H. Mattus, and R. D. Hunt, "Kinetic Testing of Nitrate-Based Sodalite Formation Over the Temperature Range of 40 to 100 C," ORNL/TM-2001/117 (Draft), Oak Ridge National Laboratory, Oak Ridge, Tenn., April 13, 2001.

${ }^{3}$ M. Z. Hu, M. T. Harris, and C. H. Byers, "Nucleation and Growth for Synthesis of Nanometric Zirconia Particles by Forced Hydrolysis,” J. Colloid Interface Sci. 198, 87-99 (1998).

${ }^{4}$ J. Addai-Mensah, "Sodium Aluminosilicate Scale Formation in Westinghouse Savannah River Company 2H Evaporation Process," Report No. 1 of Westinghouse Savannah River Company subcontract AC18106S, Ian Wark Research Institute, University of South Australia, Mawson Lakes, Adelaide, Australia, May 18, 2001.

${ }^{5}$ M. Z. Hu, D. W. DePaoli, and D. T. Bostick, "Dynamic Particle Growth Testing: Phase 1 Studies," ORNL/TM-2001/100, Oak Ridge National Laboratory, Oak Ridge, Tenn., June 18, 2001. 
This page intentionally left blank.

Page 44 of 44 